\title{
Research Paper \\ Dyslexia and the Visual- Spatial Talents: A Critical Review of New Difference- Oriented Research
}

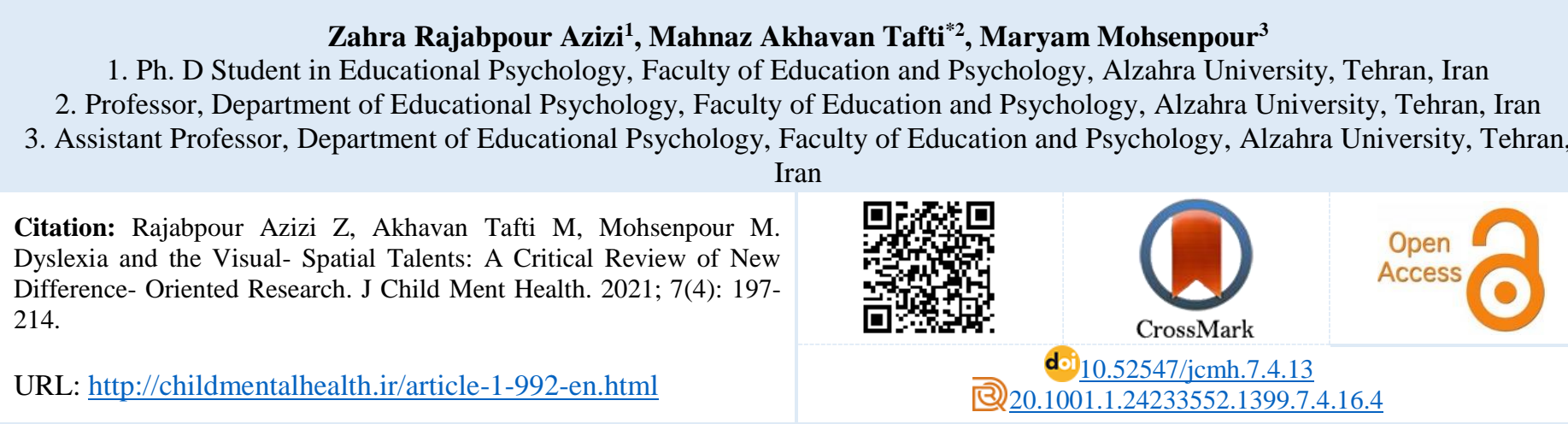

\section{A R T I C L E I N F O}

\section{Keywords:}

Dyslexia, visual-spatial talents, neurodiversity

Received: 14 May 2020 Accepted: 26 Aug 2020 Available: 18 Mar 2021

\section{A B S T R A C T}

Background and Purpose: Since the beginning of the identification of dyslexia problems, most research in this field has been based on medical and deficit-oriented approaches, all of which emphasize mostly on the existence of defects and disorders. However, over the past few decades, several studies have shown that dyslexia does not necessarily mean impairment but it is a different form of mental processing that is rooted in a diverse neurological functioning. Some findings specifically propose that individuals with dyslexia have different and even some superior visualspatial talents. However, the limited experimental evidence has yielded conflicting results. The aim of the present study was to investigate this issue by focusing on the research on the differences between visual-spatial processing and the existence/lack of such capabilities in individuals with dyslexia.

Method: This research is a kind of descriptive-critical review study. Extensive searches were performed in Iranian and international databases, including SID, Magiran, Ensani, Civilica, Web of Science, ERIC, EBSCO, ScienceDirect, PubMed, Psych INFO and Google Scholar, using the following keywords: dyslexia, reading disorder, reading disability, visual-spatial perception, visualspatial ability, creativity in dyslexia, nonverbal skills, neurodiversity, and difference-oriented approach. After preliminary study of 124 papers, the unrelated studies were excluded, and 28 papers entered the analysis stage. Data were analyzed by PRISMA model.

Results: Examination of selected papers showed that in 18 tests $(20.5 \%)$ the performance of participants with dyslexia was higher than their non-dyslexia counterparts. In 36 tests $(40.9 \%)$ the difference in visual-spatial performance between dyslexia and non-dyslexia group was not significant, and the performance of dyslexic group was equivalent to that of non-dyslexic group. Results of 34 tests (38.6\%) showed that dyslexic group had a lower performance compared to the non-dyslexic participants.

Conclusion: The findings show that the performance of the dyslexics was better in the overall understanding of the whole image, holistic processing, and representation of complex and impossible figures, and they showed a faster reaction time. But there is little evidence to support the existence of visual-spatial talents in all the visual perceptual areas among individuals with dyslexia. Finally, with various research limitations such as the selection of samples with different developmental and training levels and from various age groups, the different methodologies, and the assessment tools used in each study, achieving a more accurate profile of the cognitive strengths and weaknesses of individuals with dyslexia requires further research.

* Corresponding author: Mahnaz Akhavan Tafti, Professor, Department of Educational Psychology, Faculty of Education and Psychology,

Alzahra University, Tehran, Iran.

E-mail: Makhavan@alzahra.ac.ir

Tel: (+98) 2122141755

2476-5740/ (C) 2021 The Authors. This is an open access article under the CC BY-NC-ND license

(https://creativecommons.org/licenses/by-nc-nd/4.0/). 


\section{Extended Abstract}

\section{Introduction}

Dyslexia is among the most common forms of specific learning disorders (SLD). In the Fifth edition of the Diagnostic and Statistical Manual of Mental Disorders (DSM-5), SLD is included in the general category of neurodevelopmental disorders (1). The prevalence of dyslexia among children is about $4-10 \%$ of populations from different cultures (2). So far, most studies on the identification of dyslexia-related problems have been based on medical and deficit-oriented approaches, all of which emphasize the existence of defects and disorders (45). However, over the past few decades, there has been growing research emphasizing that dyslexia does not necessarily mean impairment but it is a different form of mental processing and functioning, rooted in neurodiversity. There is also some emerging evidence that dyslexia is not associated with deficits only, but some individuals with dyslexia have visual-spatial strengths (13-14). The idea that the visual-spatial ability of the right hemisphere may be associated with dyslexia was first proposed by Orton as cited by Akhavan Tafti, Heidarzad $h$ and Khademi (15). Other researchers such as West (16) and Wang and Yang (17) believe that dyslexia is associated with some visual-spatial talents. Geschwind and Galaburda (18) have pointed to the greater number of people with dyslexia in occupations requiring visual-spatial skills and various professions such as arts, engineering, and architecture. Other researchers have also shown that individuals with dyslexia perform better than nondyslexic people in tests of impossible figures (20), virtual reality (23), creativity (42), and drawing skills (45).

Still, the limited empirical data on the visual-spatial abilities of people with dyslexia have yielded mixed results. The assumption that dyslexia is associated with higher visual-spatial ability needs to be examined more broadly and critically. Hence, this study aimed to provide a systematic review of experimental research investigating the visualspatial abilities of people with dyslexia. This study also intended to discuss the educational implications of previous research that may be beneficial to the development and adaptation of educational methods to support students with dyslexia.

\section{Method}

This descriptive critical review was conducted in several stages (formulating the research question, collecting the data, and analyzing and explaining the findings) based on the Preferred Reporting Items for Systematic Reviews and Meta-analyses (PRISMA) model. Extensive searches were performed in Iranian and international databases (SID, Magiran, Ensani, Civilica, Web of Science, ERIC, EBSCO, ScienceDirect, PubMed, Psych INFO) and Google Scholar, using the following keywords: dyslexia, reading disorder, reading disability, visual-spatial perception, spatial ability, creativity in dyslexia, nonverbal skills, neurodiversity, and difference-oriented approach.

The papers published in credible journals from 1995 to 2019 were extracted from these databases. The initial search yielded 124 papers. At this stage, eight duplicates were omitted. Then, the titles and abstracts of the other 116 papers were reviewed, and 52 papers were eliminated since they did not meet the inclusion criteria. The remaining 64 papers were then inspected. At this stage, another 36 papers were excluded due to presenting insufficient information about the objectives of the research. Finally, 28 eligible papers were analyzed. All the authors assessed the quality of the selected papers, especially their methodology and findings.

The inclusion criteria were: English or Persian quantitative studies that examined dyslexia, reading disorder, neurodiversity, and identifying the strengths / weaknesses of dyslexics. There were also articles examining visual-spatial abilities, creativity, and other competencies of dyslexics were not included in the search due to the exploratory nature of the topic, age range, educational level, participants' sex, and time range, but eventually such papers published after 1995 that were accessible were checked.

The exclusion criteria were: papers that examined competencies in other groups of people with special needs; papers on other dimensions of dyslexia (e.g., neurofeedback; cognitive, meta-cognitive, or behavioral strategies, or dyslexia along with other SLDs such as dysgraphia and dyscalculia); reviews 
and conference papers, meta-analyses, chapter summaries, and books.

\section{Results}

The search initially yielded 124 papers. Based on the titles and abstracts of the papers and considering the inclusion and exclusion criteria, after omitting the duplicate and irrelevant papers, 28 papers that were in line with the objectives of the study were reviewed and are presented here to compare the visual-spatial abilities of individuals with and without dyslexia.

Participants' educational level: Out of the 35 studies reviewed, the participants were studying at the elementary school in 13 studies $(37.1 \%)$, the middle school in two studies $(5.7 \%)$, high school in five studies (14.3\%), and both middle and high school (2.9\%) in one research. Moreover, 13 studies recruited university students $(37.1 \%)$. Thus, most of the studies focused on elementary school and university.

Methods: Out of 35 studies, all of which were quantitative, 29 studies (82.9\%) were conducted using the causal-comparative method, five studies (14.3) using correlational methods, and only one research (2.9) using the experimental method.

Sampling method: The majority of studies $(n=23$, $65.7 \%$ ) were conducted by convenience sampling, and only $4(11.4 \%)$ studies were carried out by random sampling.

Instruments: Various tests were employed for the identification and assessment of people with dyslexia. In the present review, only tests pertaining to visual-spatial abilities, creativity, and drawing skills that were in line with the objectives of this study were examined.

Comparing the performance of individuals with and without dyslexia in visual-spatial tasks: In 18 tests $(20.5 \%)$, the performance of participants with dyslexia was superior to that of participants without dyslexia. In 36 tests $(40.9 \%)$, the difference in visual-spatial performance of individuals with and without dyslexia was not significant. In 34 tests $(38.6 \%)$, the performance of participants with dyslexia was lower than their non-dyslexic counterparts. In most papers, several tests were used to measure visual-spatial ability. Overall, 88 tests in these 35 studies were used to assess the performance of the two groups.

\section{Conclusion}

The purpose of this study was to compare the visualspatial abilities of individuals with and without dyslexia. There is some research evidence that have emphasized on the existence of such abilities in individuals with dyslexia (15-18). Although, such experimental evidence is statistically contradictory. The main question of the present study was whether individuals with dyslexia have superior visualspatial abilities? To answer this question, the related research from years 1995-2019 were reviewed critically within the study's framework.

The findings show that the performance of participants with dyslexia was better in terms of the overall understanding of the whole image, holistic processing, representation of complex and impossible figures, faster reaction time (20), virtual reality tests (23), creativity tests (42) and drawing (45), compared to individuals without dyslexia. Nevertheless, evidence supporting the existence of visual-spatial talents in all visual-perceptual domains among individuals with dyslexia is still insufficient (20). Various research limitations were observed in the reviewed studies: the selection of samples with different developmental and educational levels and different age ranges, and employing varied methodologies and assessment tools in each study, which may explain the inconsistencies in results. Thus, more studies are required in order to find a more precise cognitive profile of the strengths and weaknesses of the target group.

Based on the findings of this review, one cannot expect people with dyslexia to have and demonstrate superior creative and visual-spatial skills. Still, by taking into account their cognitive profile and strengths and weaknesses based on the differenceoriented approach, better educational conditions and interventions can be provided to them. Furthermore, by using three-dimensional tools, educational and artistic software, and the multisensory structured approach, the educational setting can be tailored to the needs of the dyslexics.

The majority of studies reviewed here included a control group, and no within-group study was found. 


\section{Quarterly Journal of Child Mental Health}

Vol. 7, No. 4, Winter 2021

Moreover, there may have been other studies on the visual-spatial abilities of the dyslexics that had been left out due to the limitations in accessing all scientific databases.

\section{Ethical Considerations}

Compliance with ethical guidelines: This study was conducted after receiving an ethics code from Alzahra University (No. IR.ALZAHRA.REC.1399.003).
Funding: This study was conducted without any financial support from any organization or institution, and it is extracted from the Ph.D. dissertation of Zahra Rajabpour Azizi.

Authors' contribution: This paper is part of the Ph.D. dissertation of Zahar Rajpour Azizi, PhD student (Alzahra University), under the supervision of Dr. Mahnaz Akhavan Tafti, and with Dr. Maryam Mohsepour as the advisor, which was approved on 1398/10/17.

Conflict of interest: The authors have no conflict of interest to report related to this manuscript.

Acknowledgments: All the individuals who made contribution in conducting this study are highly appreciated. 


\title{
نارساخوانى و توانايیىهاى ديدارى-فضايى: مرورى انتقادى از ثخوهشهاى نوين تفاوت-محور
}

\author{
زهرا رجب يور عزيزى'، مهناز اخوان تفتى “'، مريم محسن يور"

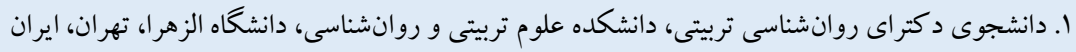

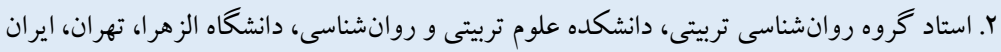

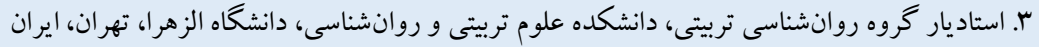

زمينه و هدف: بيشتر يثوهش ها درباره شناسايى مشكلات نارساخوانى از ابتدا تاكنون، مبتنى بر روى آورد بزشكى و آسيبمحور بوده است

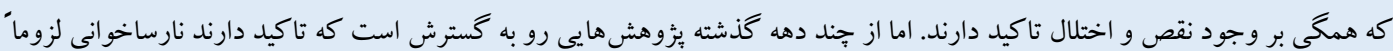
به معناى نقص و آسيب نيست، كه شكل متفاوتى از كار كردهاى ذهنى - بردازشى است و در گوناكونى عصبشناسى ريشه دارد؛ بهويزه اين كه افراد نارساخوان از استعدادهاى ديدارى - فضايى متفاوت و حتى برترى برخوردارند. با اين حال دادههاى تجربى محدود در زمينه

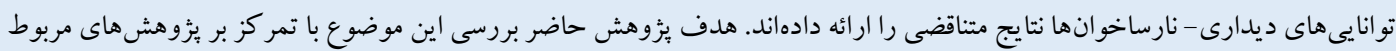

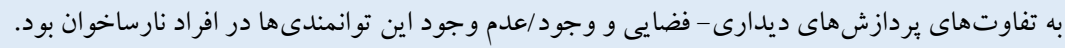

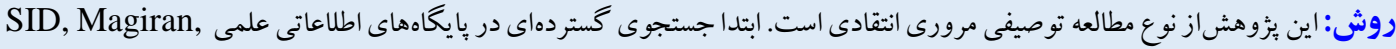
Ensani, Civilica, Web of Science, ERIC, EBSCO, ScienceDirect, PubMed, Psych INFO and Google Scholar,

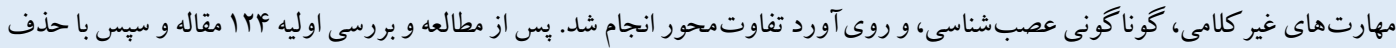
مطالعات نامرتبط، ^Y مقاله با روش يريزما به مرحله تحليل وارد شد.

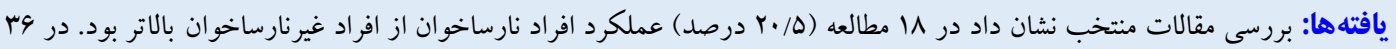
مطالعه (9/••ادرصد) تفاوت عملكرد ديدارى- فضايى بين افراد نارساخوان و غيرنارساخوان معنادار نبود و عملكرد گرووه نارساخوان معادل با افر اد غيرنارساخوان بود. در MF مطالعه (TN/9 درصد) عملكرد افراد نارساخوان بايين تر از غيرنارساخو ان بود.

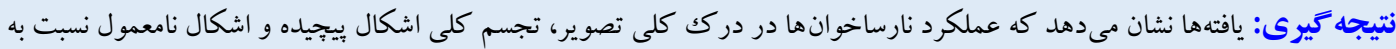

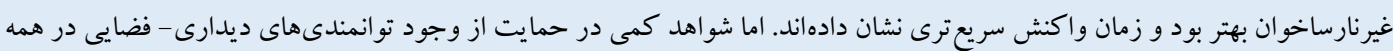
زمينها در افراد نارساخوان وجود دارد. درمجموع با وجود محدوديتهاى بزوهشى مانند انتخاب نمونههايى از گروههاى سنى، تحولى و و آموزشى متفاوت؛ يكسان نبودن روشها؛ و ابزارهاى سنجش به كار رفته در هر يزوهش، رسيدن به نيمرخ شناختى دقيقتر از نقاط قوت و

* نويسنده مسئول: مهناز اخوان تفتى، استاد گروه روانشناسى تربيتى، دانشكده علوم تربيتى و روانشناسى، دانشگاه الزهرا، تهران، ايران.

Makhavan@alzahra.ac.ir رايانامه:

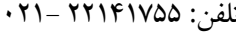


عصـب شـناختى r اسـت. در اين نظريه تأكيد شـده است در كنار توجه به

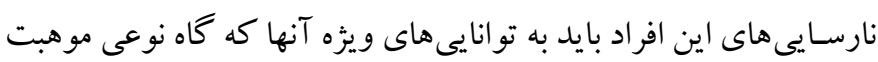

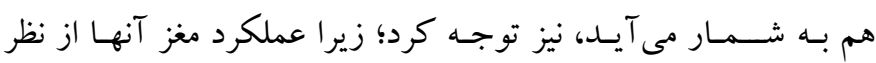
عصب شناختى با افر اد با تحول بهنجار متفاوت است (If).

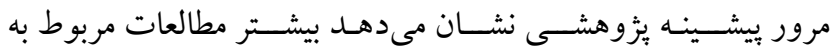

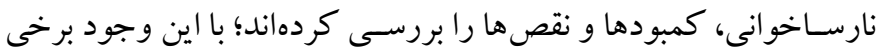

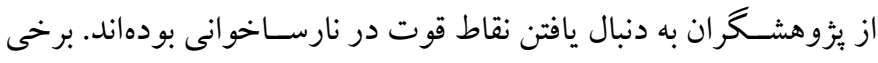

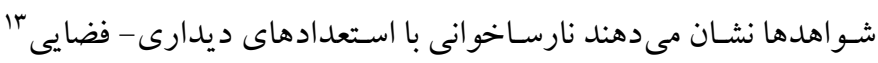

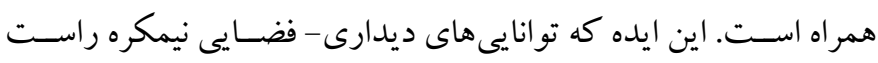

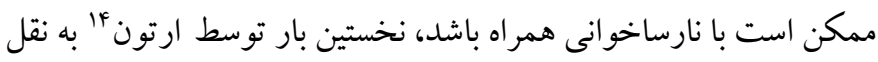

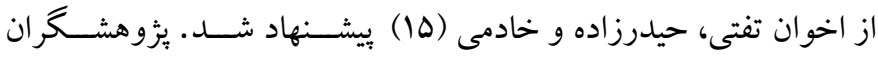

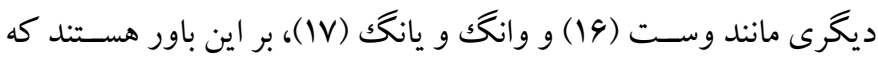

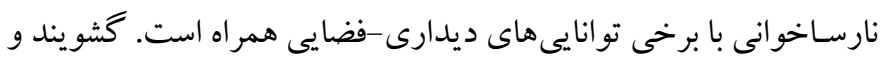

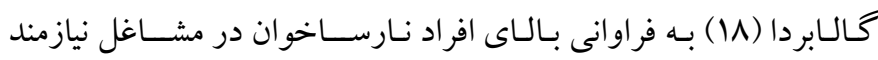

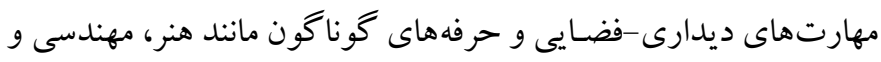
معمارى اشـاره كردند. آنها در نظريهشـان اشـاره كردهاند كار كرد بايين

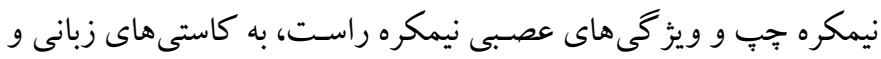

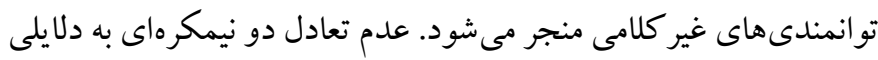

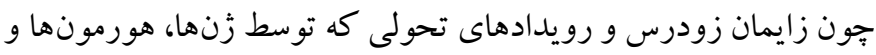

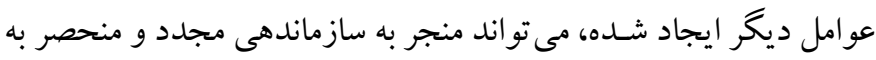

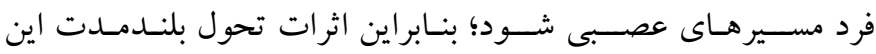

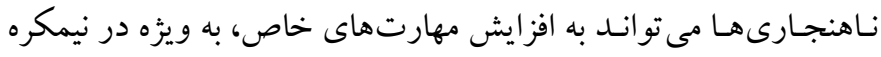
راست مغز كمكك كند.

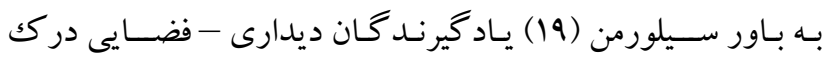

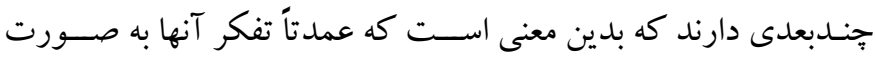
ديدارى، شهودى، و غيرخطى است. آنها به صورت متوالى و حفظ كردن

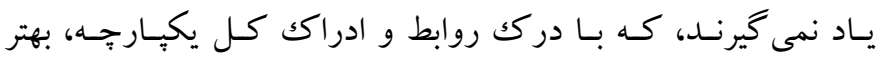

\section{Subitizing}

9. Social model of disability

10. Attention deficit hyperactivity disorder (ADHD)

11. Differences- oriented

12. Neurodiversity

13. Visual-spatial strengths

14 .Orton
مقدمه

در ميان دانش آموزان با نيازهاى ويزه'، دسـتهاى از آنها با وجود داشـتن

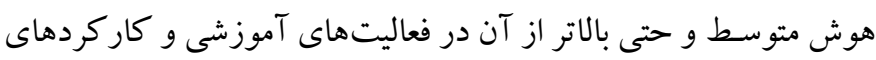

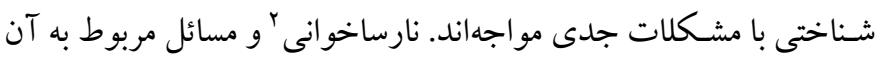

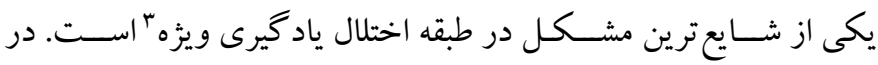

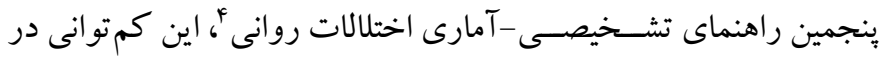

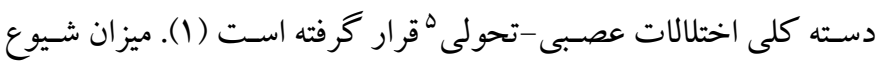

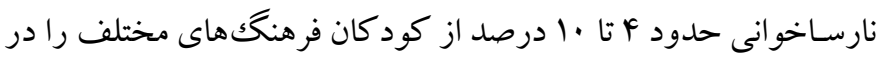

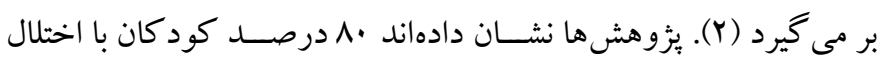

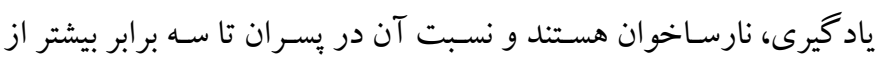

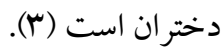
در روى آورد بزشـكى و و سـاير مدلهاى آسـيب- محور، همخكى بر

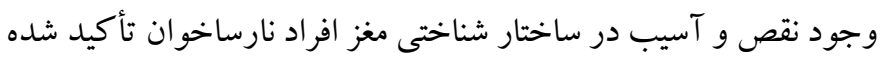

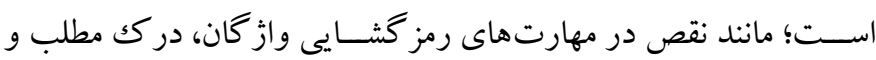

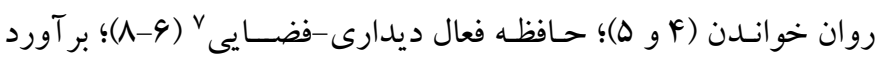

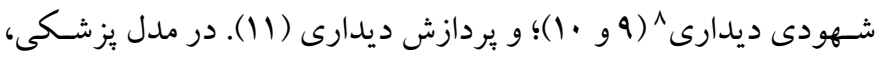
كم توانى به عنوان نقص در نظر كرفته مىشـود كه اين نقص مانع بيشـبرد

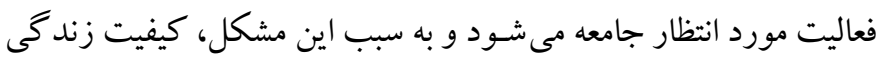

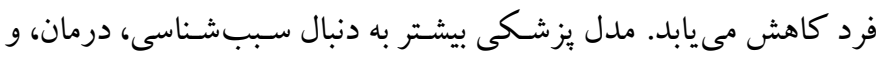

ييامدها است و به نرمالسازى و كاهش نشانكان، اشتياق دارد (Y ( ).

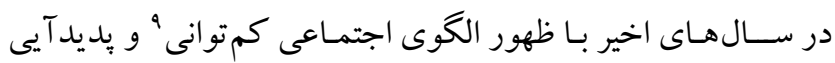

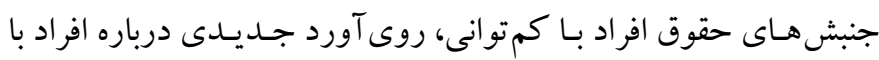

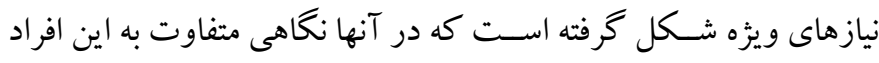

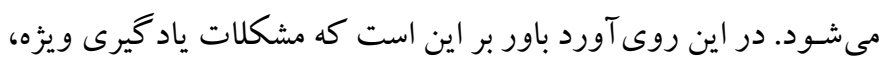

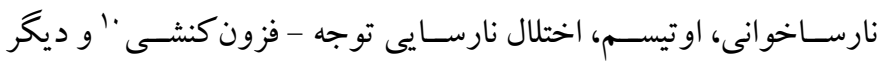
اختلالات حوزه عصب شناختى را بايد به عنوان تفاوت و نه فقط به عنوان

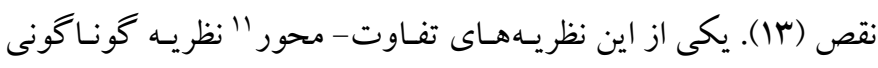

1. Special needs

2. Dyslexia

3. Specific learning disorders

4. Diagnostic and Statistical Manual of Mental Disorder, Fifth edition (DSM-5)

5. Neurodevelopmental disorders

6. Medical model

7. Visual-spatial working memory 
مطالعه حاضـر مرور سـازمانيافته بِيشـــنهاى يُزوهشى تجربى اسـت كه

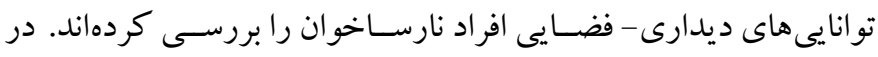

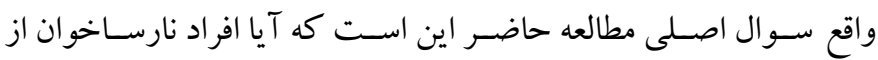
توانايى هـاى ديدارى - فضـايى برترى برخوردارند؟ همجنين اين مطالعه درصـدد اسـت ضـمن مرور و نقد بيشـينه يُزوهش هاى انجام شـده قبلى و ياسـخ به اين سوال، دلالتهاى آموزشى آن را نيز در راستاى حمايت از

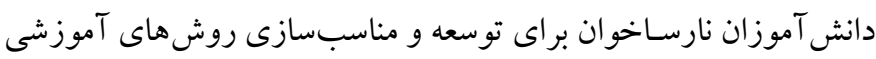

$$
\text { مورد بحث قرار دهد. }
$$

روش

روش مطالعه حاضر از نوع توصيفى و مرورى انتقادى بود. در خند مرحله

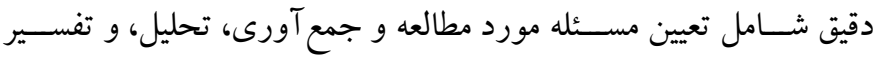

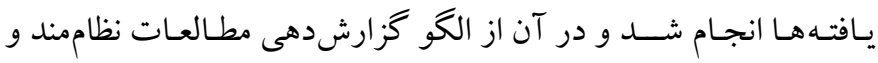

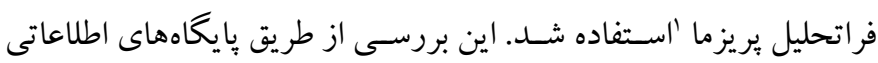
علمى جهاد دانشـاهى (SID :Scientific Information Database) بانكك اطلاعات نشـريات كشـور (Magiran)، بر تال جامع علوم انسـانى Web of و سـيليويكا (ENSANI) و بـايغاههاى اطلاعاتى (civilica) Psyc INFO ، PubMed ،ScienceDirect ،ERIC ،EBSCO، Science و موتور جستجوىGoogle Scholar انجام شد. در اين بخش براى شــناسـايى و ززينش منابع مرتبط با كليد وازههاى

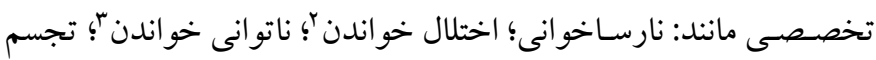

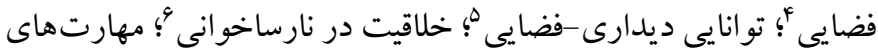

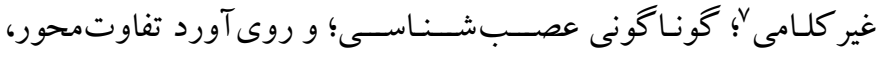

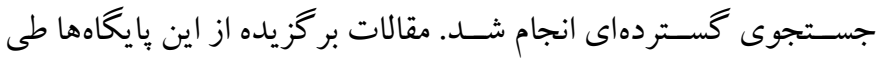

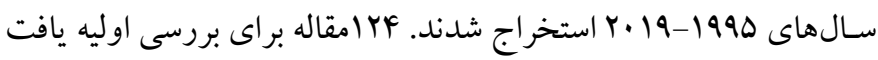

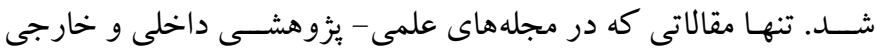
جاٍ شـــه بودند، جهت مطالعه انتخاب شـــند. در اين مرحله م مقاله به دليل تكرارى بودن حذف شد. سبس عناوين و جكيده 119 مقالات ديخر بررسـى شــــ و از اين تعـداد كه مقاله به دليل مرتبط نبودن با معيارهاى

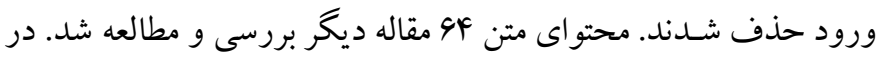

4. Visual-spatial perception

5. Spatial ability

6. Creativity in dyslexia

7. Nonverbal skill

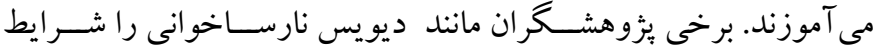
خودســاختـهاى مي دانـد كـه در نتيجـه تفكر برتر ديـدارى- فضـــايى و يردازشـى كه بسـيار سـريع تر از تفكر كلامى اسـت، رخ مىدهد و آن را نوعى موهبت توصيف مى كند كه سودمندىهاى زيادى دارد (ها). همجينين برخى يزٔوهش ها نشـان مى دهند بين نارسـاخو انى و سـرعت شــــــــــــــــــــال اشعامعول ارتباط وجود دارد و افراد نارســاخوان توانايىهاى هنرى و تجسـم ديدارى - فضايى خوبى دارند ( •Y)؛ اما مرور يثزوهشها نشان مى دهد اين موهبت بر مبناى شواهد يزٔوهشى اندكى قرار دارد و عمـــتاً بر اســاس اطلـاعـات در دســترس، نمونـهــاى انـدك و كز ارش هاى سـو گير انه افر اد توصسيف شـده اسـت. در واقع بثزوهش هاى تجربى دربـاره توانـايىهـاى ديدارى- فضــايى افراد نارســاخوان، نتايج

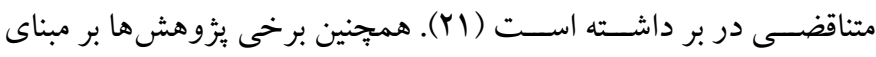
مصساحبه با افر اد نارسـاخوان انجام و گز ارش شـده است كه نشان مىدهد افراد نارسـاخوان در مشاغل هنرى، مديريتى، معمارى، و كار آفرينى بسيار موفقاند (Y M و YY)؛ اين در حالى اســت كه برخى يزٔوهش ها بين تو انايى ديدارى- فضــايى و نارسـاخوانى ارتباطى مشــاهده نكردهاند (Y4-YY). همجينين در مرور بيشينه هاى داخلى درباره تو انايى ديدارى- فضايى افراد نارسـاخوان مى توان به يزوهش هاى اخوان تفتى، حميدى و محمدى (I Y) اشــاره كرد كه نشـان دادند خلاقيت و حافظه ديدارى افر اد نارســاخوان نسبت به به افرا رساخوان بالاتر، اما ادراكك ديدارى- فضايى نارساخوانها از رساخوانها، پايينتر است. همجينين يافتهاى اخوان تفتى، حيدرزاده و خادمى (ه) مؤيد آن اسـت هوش ديدارى - فضــايى افراد نارســاخوان بالاتر از همسالان بدون نارساخوانى است؛ اما يافتهاى افشاريان، ياريارى، امين الرعايا و قليجى سـكه (YV) نشـان داد توانايى ديدارى - فضـايى افراد بدون نارساخوانى بالاتر از افراد نارساخوان است. بر اين اســاس نتـايج يزوهشهـاى قبلى درباره بود / نبود توانايىهاى ديدارى- فضايى در افراد نارساخوان بسيار متناقض است. اين كمانهزنىها كه "افراد نارسـاخوان از توانايى ديدارى- فضـايى بالاترى برخوردارند"، را مىتوان از نگًاه كستردهتر و انتقادىترى بررسى كرد. از اينرو هدف

1. PRISMA: Preferred Reporting Items for Systematic Reviews and Meta-analyses

2. Reading disorder

3. Reading disability 
r. مقالات كمّى انجام شده علمى - ئزوهشى به زبان انخليسى يا

$$
\text { فارسى منتشر شده بودند. }
$$

r. مقالات به بررسى توانايى هاى ديدارى- فضايى، خلاقيت و ديخر بودندر

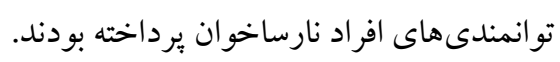

F. به دليل اكتشافى بودن موضوع محدوديت زمانى در انجام جستجو لمارس

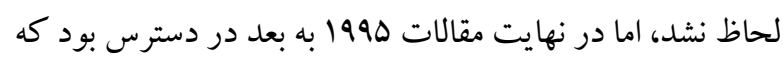

$$
\text { مورد بررسى قرار گرفتند. }
$$

معيار هاى خروج

ا. مقالاتى كه توانمندى ها را در ساير گروههاى كود كان با نيازهاى

$$
\text { ويزه مورد بررسى قرار داده بودند. }
$$

r. مقالاتى كه در حوزه ساير توانمندىهاى شخصيتى و رفتارى برى درد

$$
\text { نارساخوانها بودند. }
$$

r. مقالات مرورى، كنفرانسى، فراتحليل، خلاصه فصل ها، و كتابها

$$
\text { از اين بيزوهش حذف شدند. }
$$

اين مرحله 4ب مقاله ديخر به دليل عدم ارائه اطلاعات كافى درباره اهداف

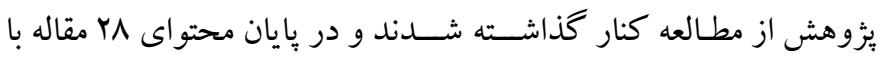

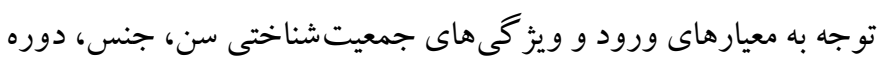

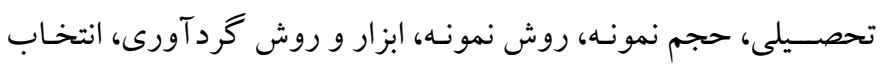

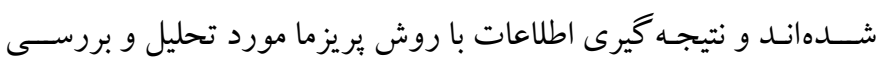

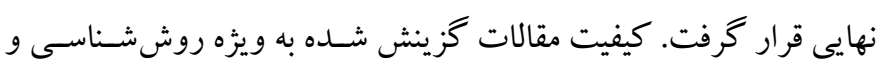

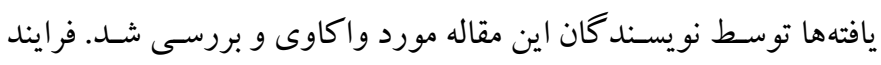

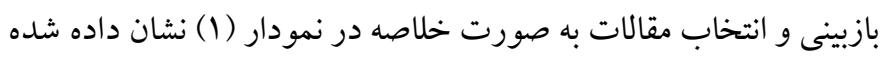

\section{معيارهاى ورود} ا. مقالاتى كه به بررسى ناتوانى هاى ياد گيرى ويزه، نارساخوانى،

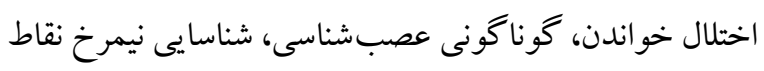
قوت/ضعف نارساخو انها يرداخته بودند.

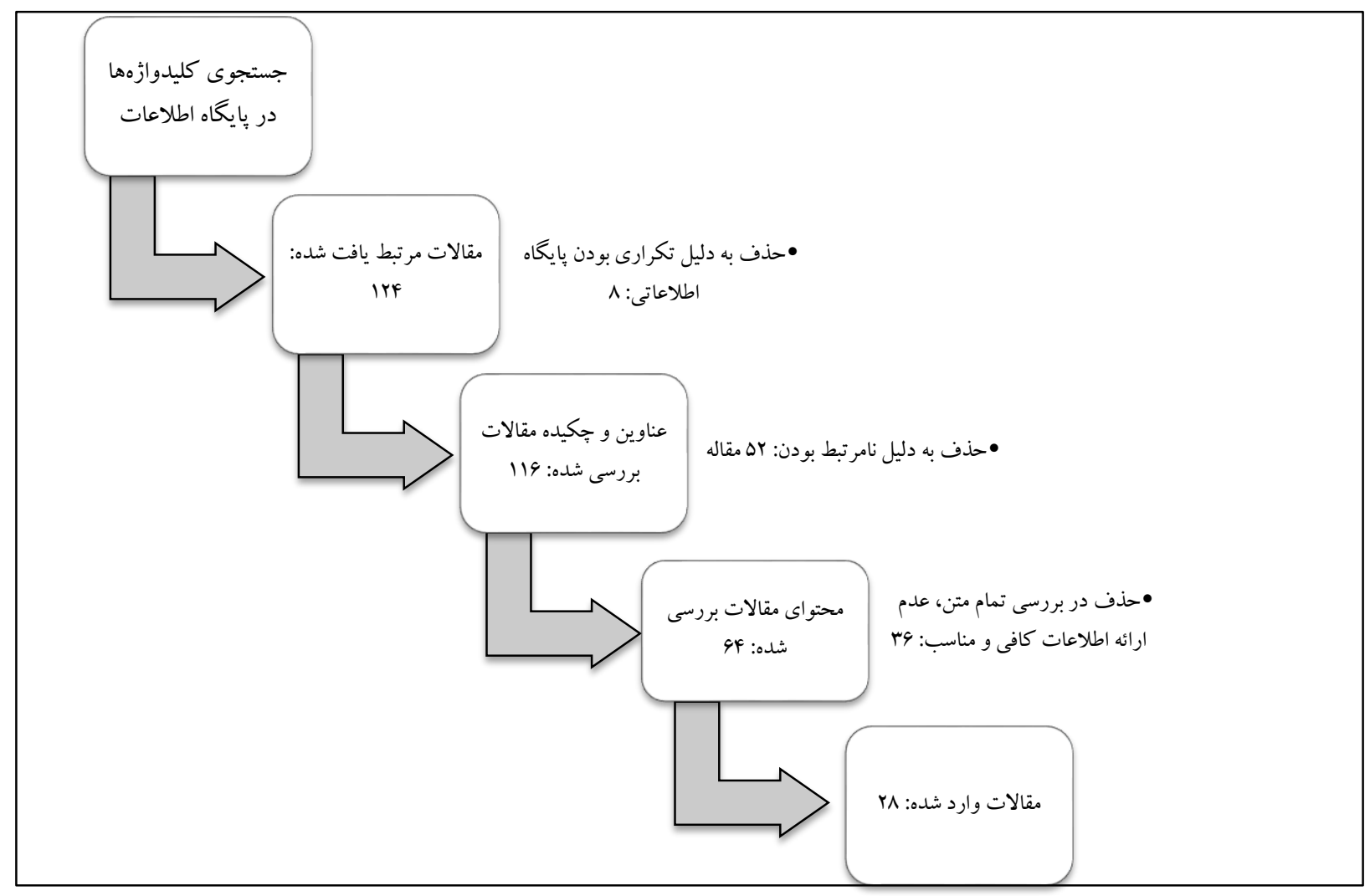

نمودار ا: فرايند غربالكرى و ورود مقالات 
مقالات و با در نظر گرفتن معيارهاى ورود و خروج، بعد از كنار گذاشستن

يافته ها

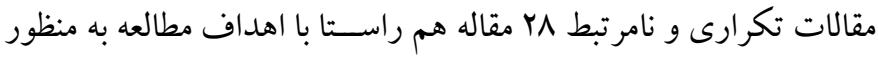
در اين مطالعه در نتيجه جستجو بر اساس اهداف ئزوهش، FF إن مقاله در

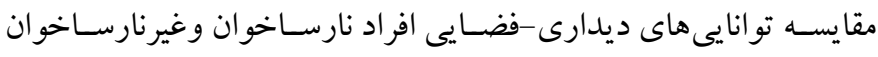

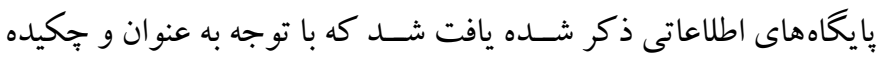
مرور و ارائه شد.

جدول ا: خلاصه اطلاعات YA مقاله مرور شده در حوزه مقايسه توانايى ديدارى- فضايى نارساخوان و غيرنارساخوان

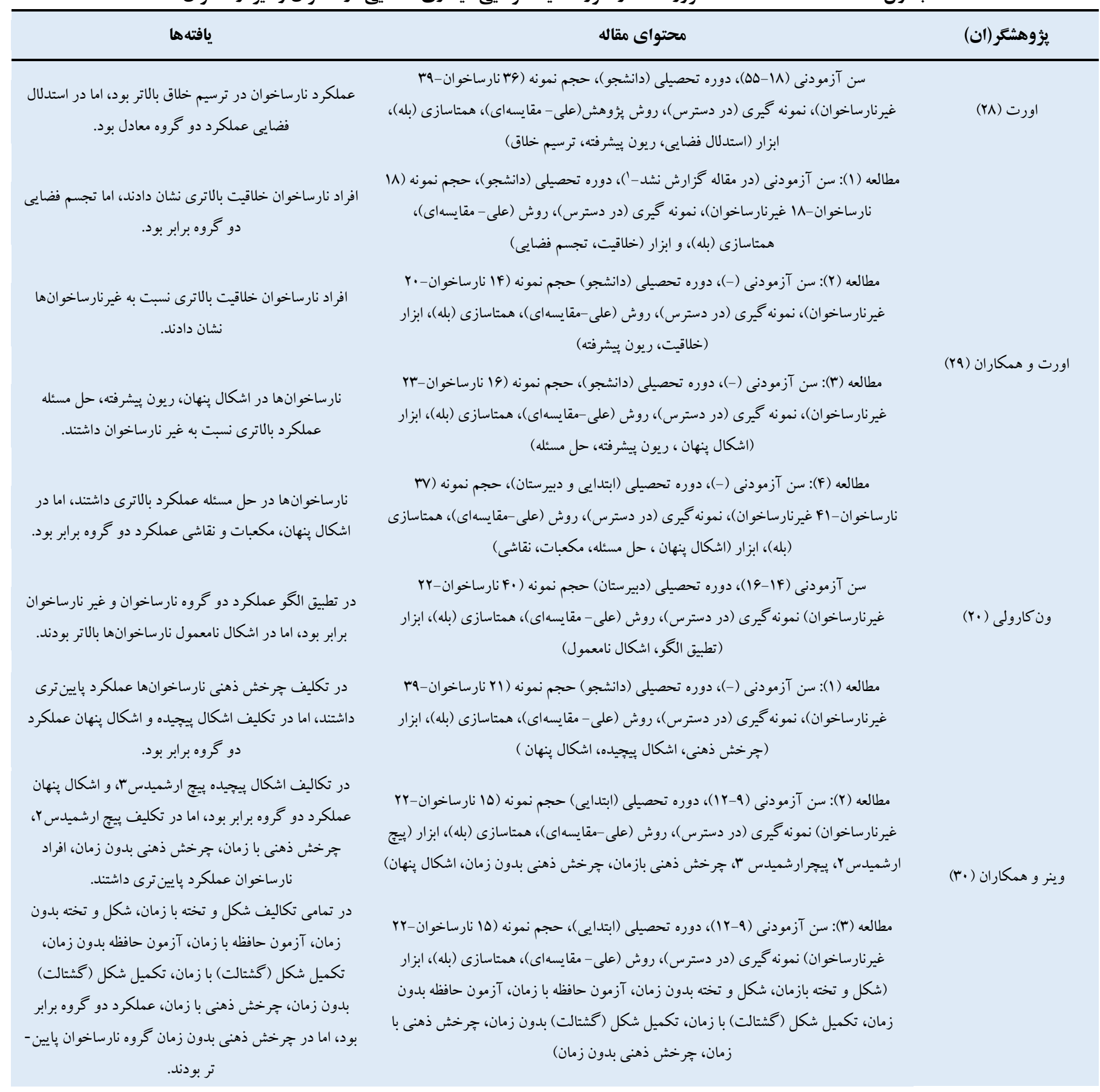

ا. در مقاله گزارش نشده بود. 
افردا نارساخوان عملكرد بهترى در تكاليف هنرى نسبت به غيرنارساخوانها داشتند.

افردا نارساخوان عملكرد بهترى در تكاليف هنرى نسبت به غيرنارساخوانها داشتند.

در تكليف اشكال نامعمول ا، عملكرد دو گ گروه برابر بود، اما در تكليف اشكال نامعمول ب نارساخوانها بايين تر بودند.

در هر سه تكليف نمادها، اشكال سه بعدى، و جرخش ذهنى

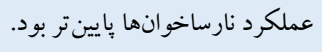

در آزمون نقاشى عملكرد دو گروه برابر بود.

عملكرد نارساخوانها در تكليف جرخش حروف يايين تر بود.

عملكرد هر دو دو گروه در تكليف جرخش شكل برابر بود. عملكرد هر دو دو گروه در تكليف جستجوى نماد،

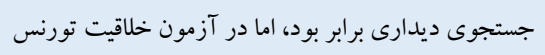
كروه نارساخوان عملكرد بايين ترى داشت.

در آزمون مجازى زندگى شبهواقعى عملكرد گروه

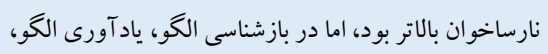
دو گروه برابر بودند.

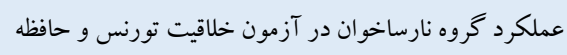
تصويرى بالاتر بود، اما در ادراكك ديدارى - فضايى عملكرد يايين ترى داشتند.

در توصيف فضاى بيرون، توصيفات ميدانى گروه نارساخوان عملكرد هيايين ترى داشتند.

\section{در هر جهار تكليف ديدارى- فضايى عملكرد گروه نارساخوان يايين تر بود.}

در تكليف جرخش (سرعت) گروه نارساخوان عملكرد بهترى داشتند، اما در تكليف جرخش (دقت) دو گروه بر برابر بودند.

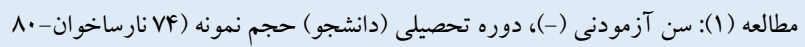

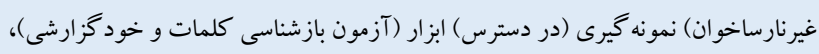

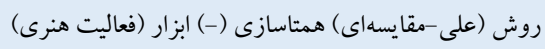

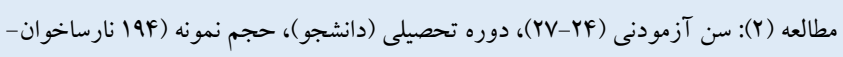
ولف و همكاران ( آ)

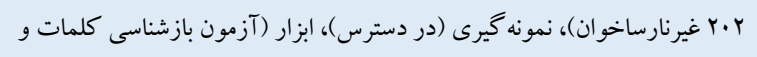

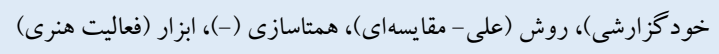

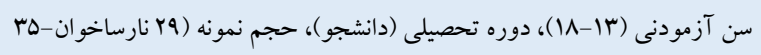

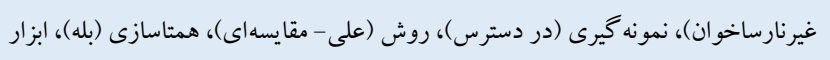

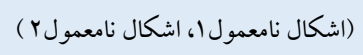

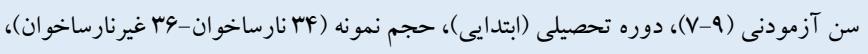

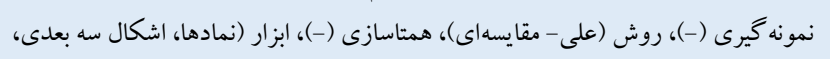

$$
\text { جرخش ذهنى) }
$$

سن آزمودنى (-)، دوره تحصيلى (ابتدايى)، حجم نمونه (·r نارساخوان-·r غيرنارساخوان)،

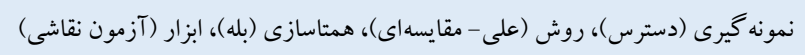

مطالعه (1): سن آزمودنى (19-1)، دوره تحصيلى (دانشجو) حجم نمونه (19 نارساخوان-1Y

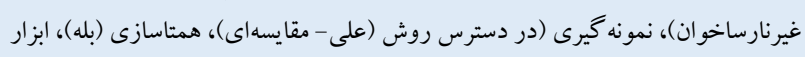

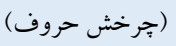

مطالعه (Y): سن آزمودنى (19-19)، دوره تحصيلى (دانشجو)، حجم نمونه (19 نارساخوان-1Y

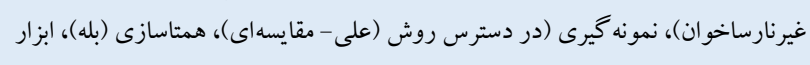

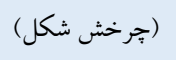

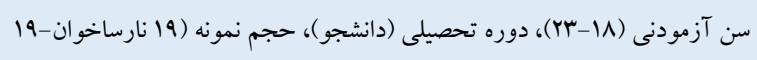

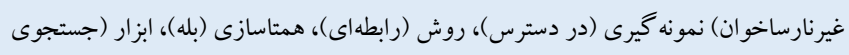

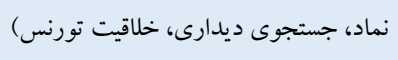

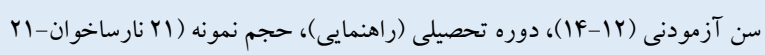

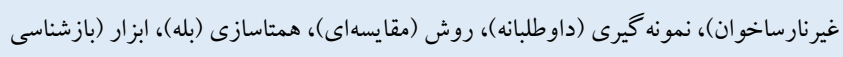

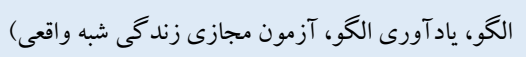

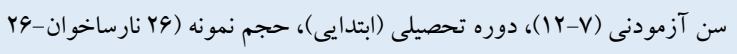

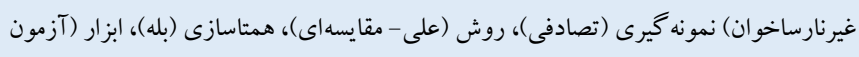

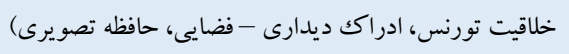

سن آزمودنى (9-9 (1)، دوره تحصيلى (ابتدايى)، حجم نمونه (11 نار ساخوان-19

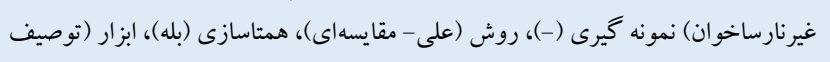

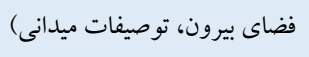

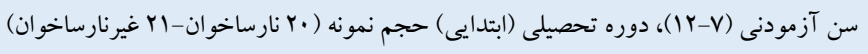

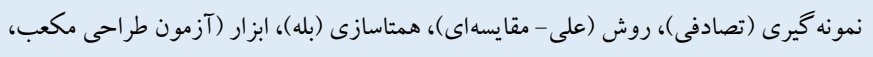

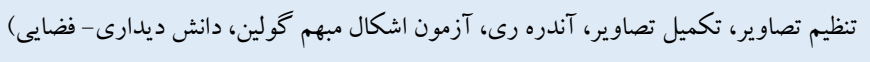

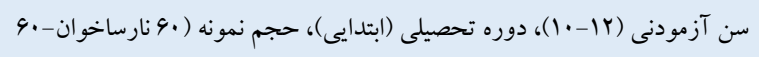

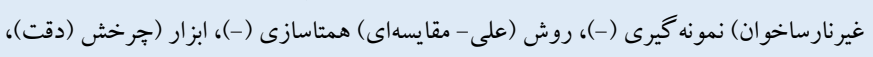
خرخش (سرعت)
كورولو و همكاران (T) روسياك (FF)

ون كارولى و همكاران (Ir) (I) روسلر و همكاران (rr) (r)

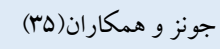

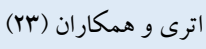

اخوان تفتى و همكاران (Ir) مامرل و همكاران (4) برونسكى و همكاران (rV) وانگك و يانگك (IV) 


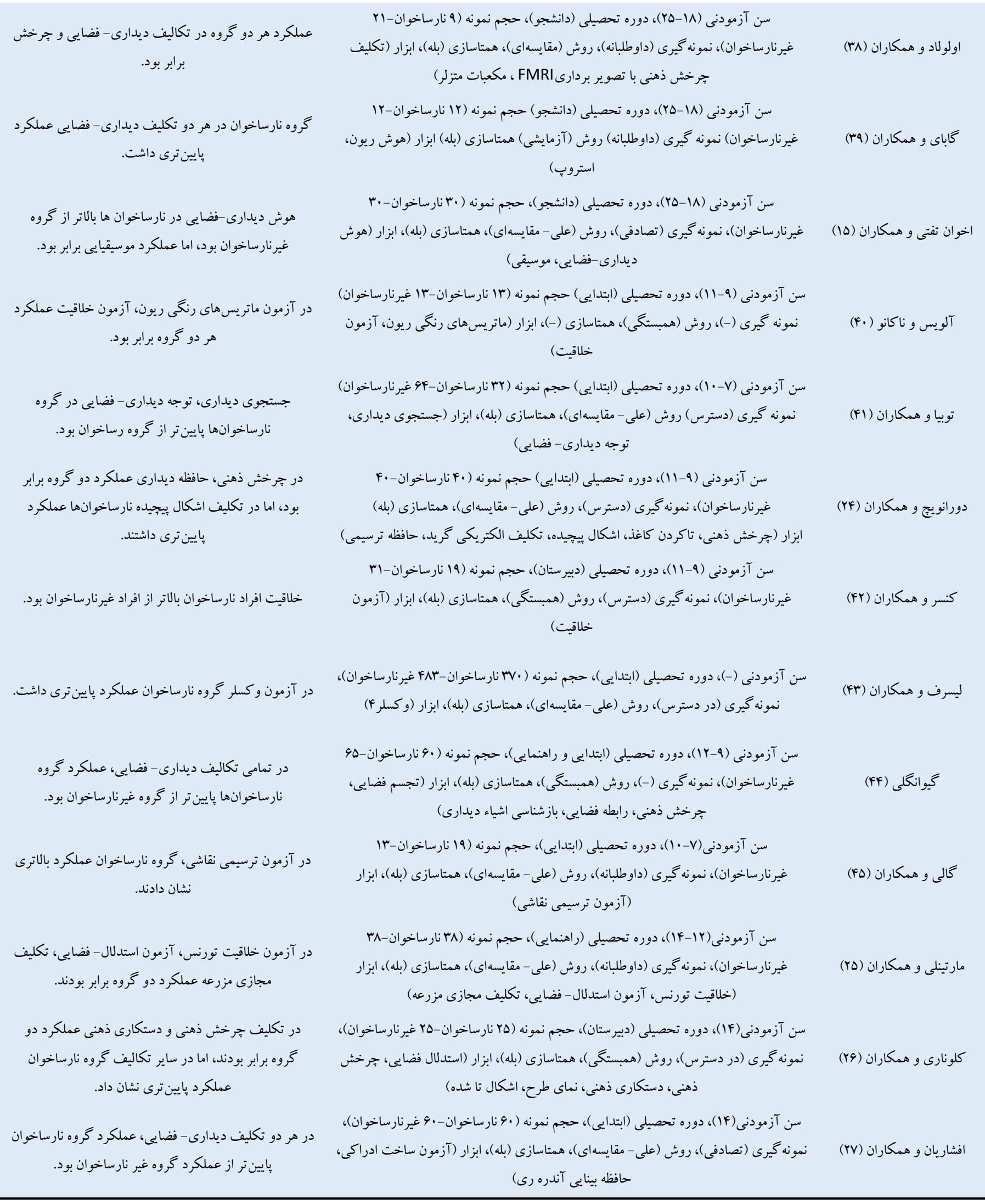


يثزوهشهـاى درونى هر مقـالـه كـهـ بـا نمونسههـا، روشهـا و ابزارهـاى جداكانهاى گزارش و تحليل شده بودند در اين مطالعه نيز گزارش آنها به

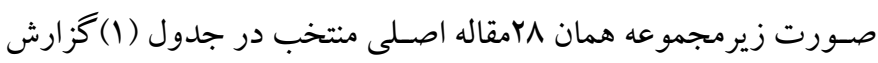
شـده اسـت. با اين توضسيح، مجموع اسـناد بررسى شده در حوزه توانايى ديدارى- فضايى در اين مطالعه ها بزوهش بوده است.
در جدول ( ) خلاصسه اطلاعات اين ب ب مقاله ارائه شـده است. در اين بخش نتايج تحليل هاى انجام شـــه در ارتباط با ســن آزمودنىها، دوره تحصــيلى، روش نمونه كيرى، روش بزؤهش، نوع ابزار و تكاليف، نتايج به دست آمده بين گروه نارساخوان و غيرنارساخوان ارائه شده است. بيان اين نكته ضـرورى اسـت اگر جهه در اين مطالعه، Y مقاله مورد بررسسى و تحليل قرار گر فت اما برخى مقالات شامل جند يزّوهش بودند. با احتساب

\section{جدول r: نتايج بررسى برخى ويزگى هاى مقالهها}

\begin{tabular}{|c|c|}
\hline نتيجه & ويزگى \\
\hline \multicolumn{2}{|c|}{ 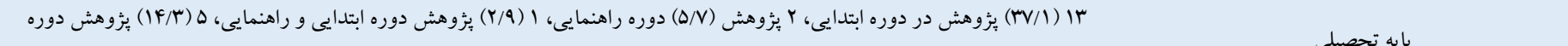 } \\
\hline \multicolumn{2}{|l|}{ 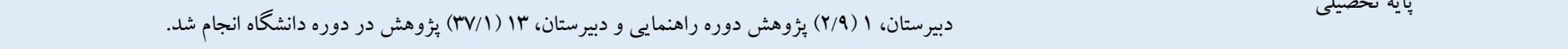 } \\
\hline \multicolumn{2}{|l|}{ 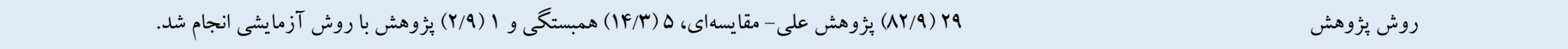 } \\
\hline 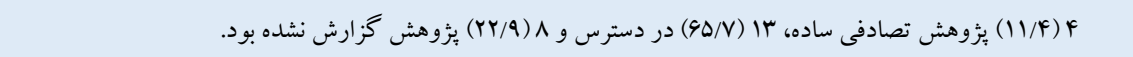 & روش نمونه گيرى \\
\hline \multicolumn{2}{|c|}{ 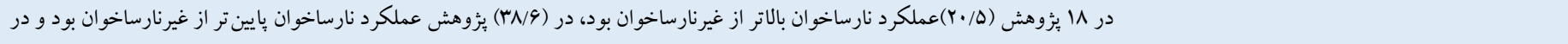 } \\
\hline 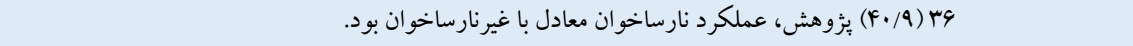 & توانايى ديدارى - فضايى نارساخوان و غيرنار ساخوان \\
\hline \multicolumn{2}{|l|}{ (للازم به ذكر است كه تمامى اعداد داخل ير انتز بر حسب درصد نوشته شدهاند). } \\
\hline
\end{tabular}

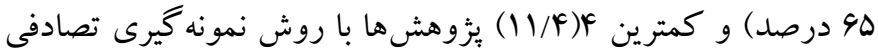
انجام شده است. مقـايسـهـ عملكرد افراد نارســاخوان و غيرنارســاخوان در تكاليف ديدارى- فضـايى: با توجه به يافتهاى جدول (Y)، و خلاصسـه تحليل

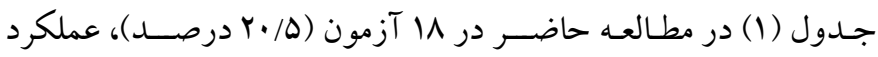

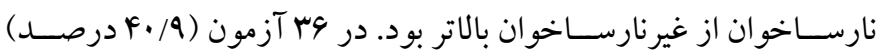
تفاوت عملكرد ديدارى- فضـيى بين نارساخو ان و غيرنارساخوان معنادار

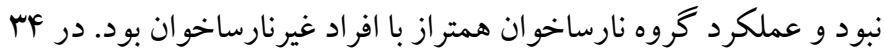

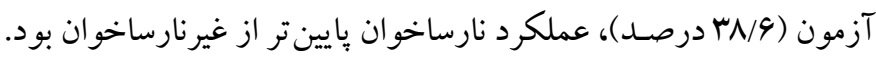

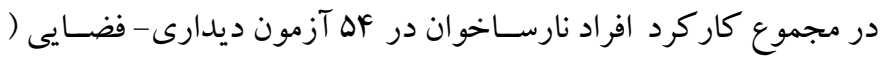

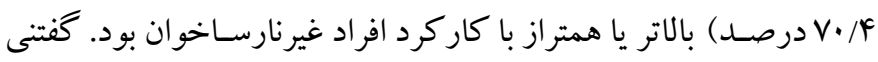
است در بيشتر مقالات براى سنجش توانايىهاى ديدارى- فضايى بيش از

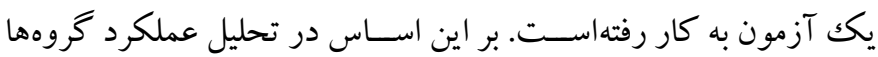

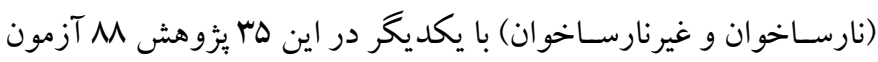
به كار رفتهاست.
دوره تحصيلى آزمودنى ها: با توجه به اطلاعات جدول (Y)، از مجموع هr بثزوهش بررسى شده در سا ئزوهش، ( IV/T درصد) در دوره ابتدايى،

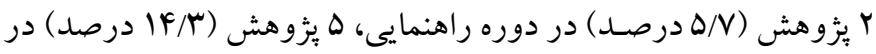
دوره دبيرســــان، إئوهش هم در دوره ابتـدايى و هم راهنمـايى (Y/9 درصـد)، ا ئزوهش هم در دوره راهنمايى و هم دبيرستان (ب/9 درصد) و سا يزٔوهش در دوره دانشـكاه (TV/I) انجام گرفته بود. بر مبناى مطالعات مرورى يزوهش هاى انجام شده در زمينه توانايىهاى ديدارى - فضايى در ارتبـاط بـا افراد نارســاخوان، تمركز بيشــتر يثزوهش ها بر دوره ابتدايى و دانشخاه بوده است. روش يخوهش: با توجه به اطلاعات جدول (Y)، از بين هب يزوهش انجام

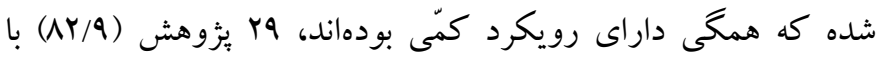

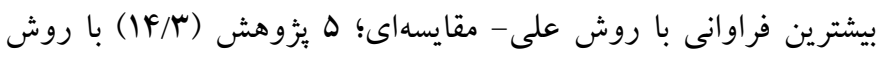
همبستخى؛ و تنها ا ئزوهش (Y/9) با روش آزمايشى انجام شده بود. روش نمونه تيرى: با توجه به اطلاعات جدول (Y)، از مجموع مقالات

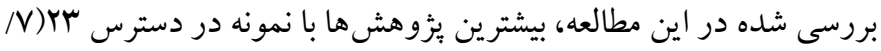




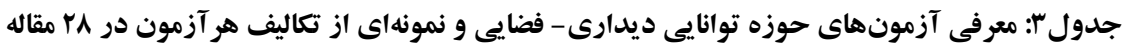

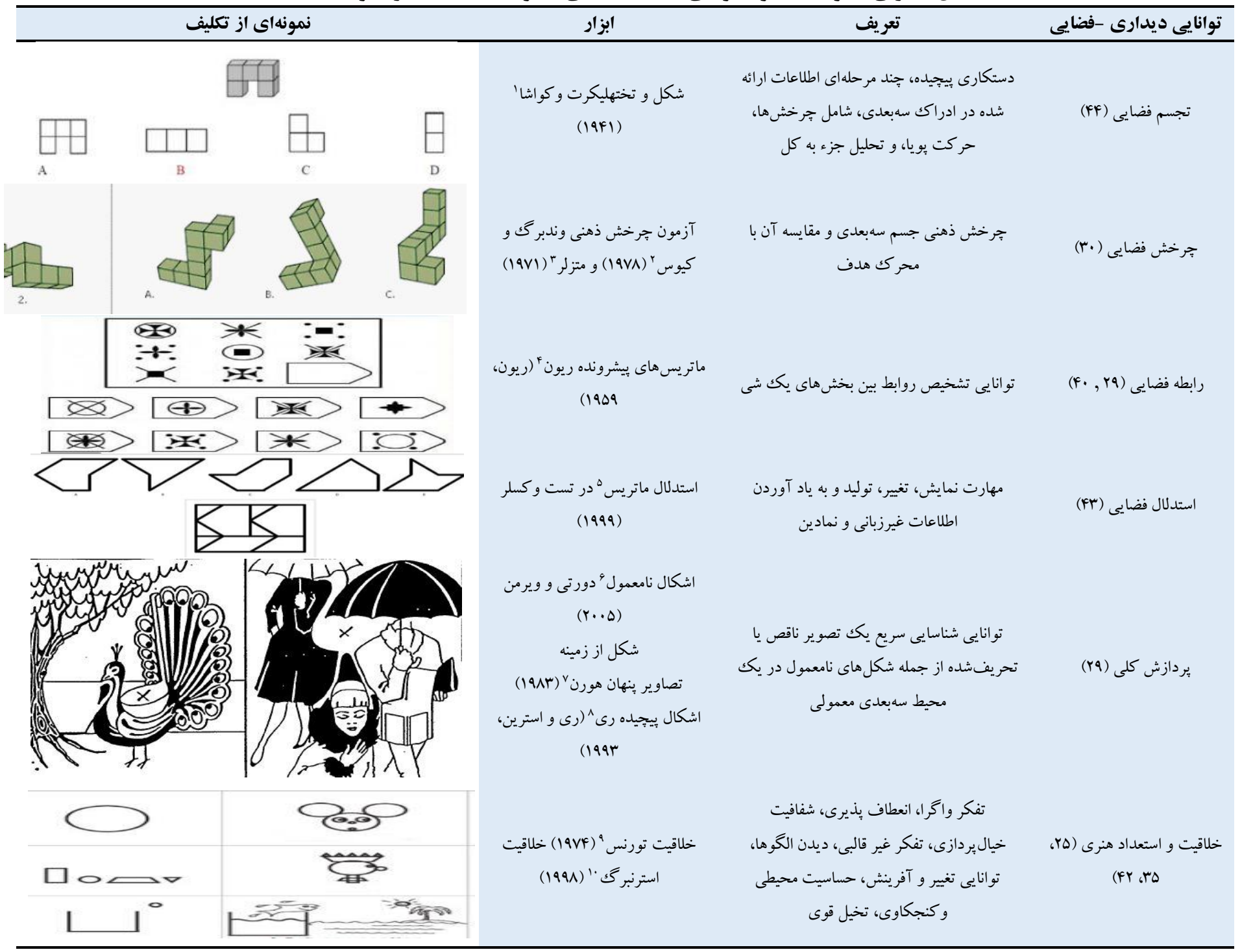

در راسـتاى اهداف اين مطالعه بود و در يزووهش هاى ارزيابى شـده به كار

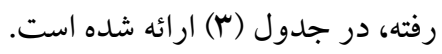

ابزار: به طور كلى آزمونهاى كوناكونى در شـناسـايى و ســنش افراد نارسـاخوان به كار رفته اسـت. در اين مطالعه مرورى صـرفاً آزمونهاى حوزه توانايى ديدارى- فضايى، خلاقيت و مهارت هاى هنرى ترسيمى كه

1. From Board Test (Likert \& Quasha, 1941).

2. Vandenberg and Kuse (1978).

3. Shephard Metzler Cubes

4. Raven's Progressive Matrice

5. Matrix reasoning

6. Impossible Figures, Gestalt Completion

7. Hidden Figures Test

8. Rey-Osterrieth Complex Figure Test stimulus from Osterrieth (1944) and Rey (1941).

9. Torrance Tests of Creative Thinking (TTCT)

10 .WCR Creativity Test (Sternberg, 1998). 
فضـايى بـا مطالعـات گوناكون متفاوت بوده و معمولا ابزارها مؤلفه هاى

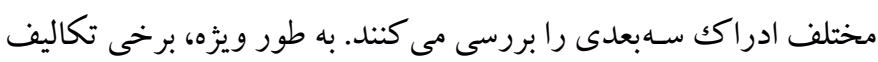

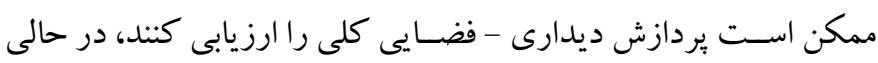

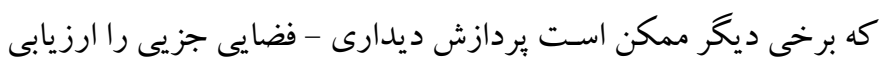
كنند.

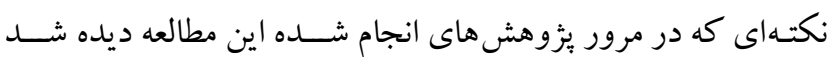

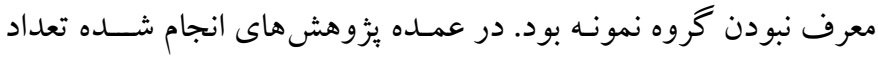

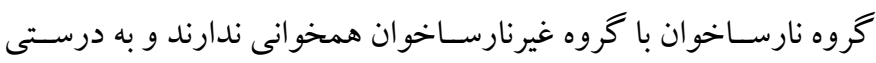

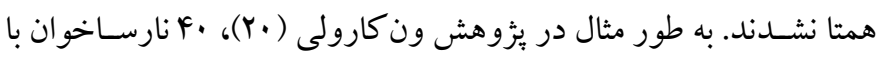

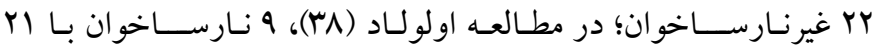

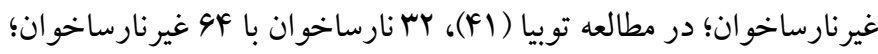

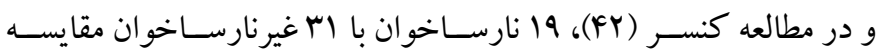

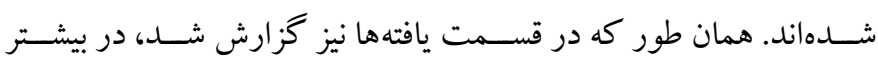

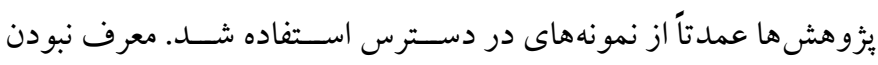

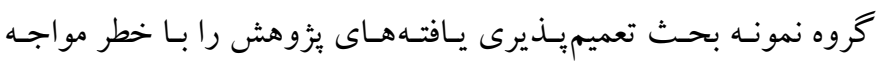

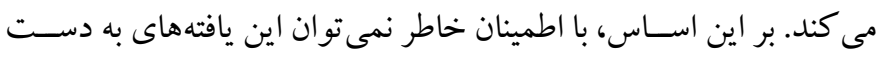
آمده را به كل جامعه نارساخوان تعميم داد. بر. برخى يـافتـها نشــان دادهاند تو انايى خو اندن كود كان نارســاخوان

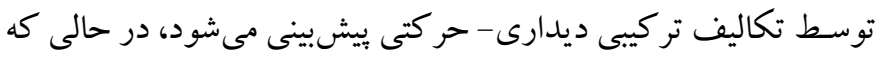

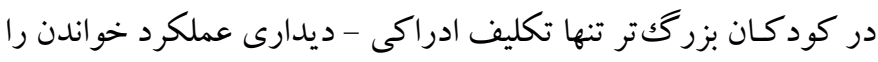

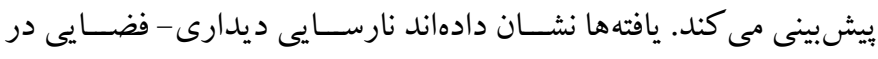

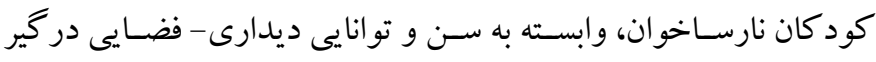

خو اندن در مر احل مختلف آموزشى، متفاوت عمل مى كند (rq).

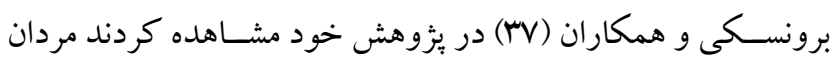

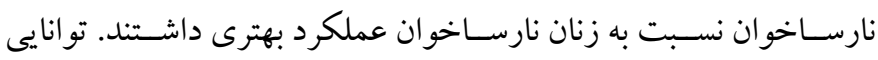

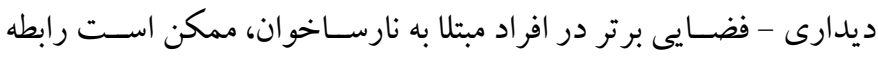

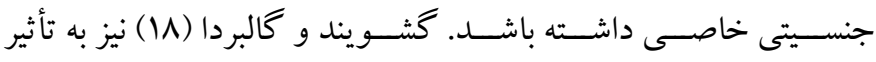
تستوسترون در تحول مغز جنين و مدل تأثير هورمونها و تغييرات زيستى داصن قبل از تولد اشاره داشتند.

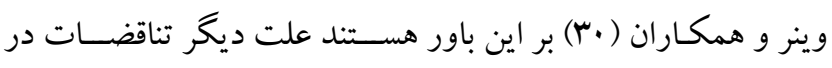

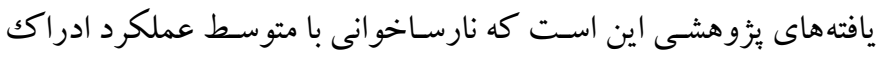

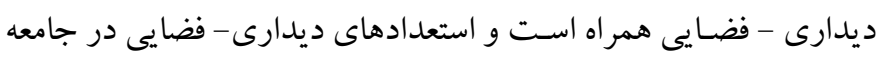

نتيجه كيرى

هدف مطالعه حاضـر مقايسـه توانيى ديدارى - فضـايى افراد نارساخوان و

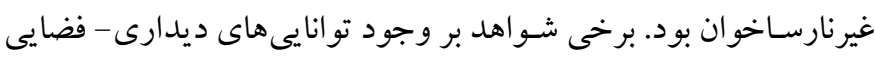

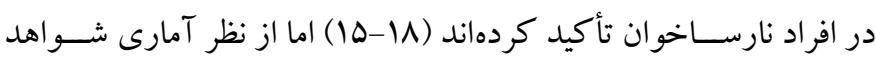
تجربى متناقض است. در واقع سوال اصلى مطالعه حاضر اين بود آيا افراد

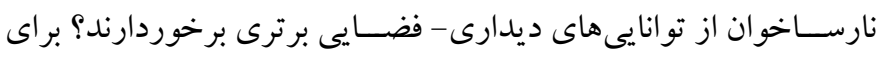

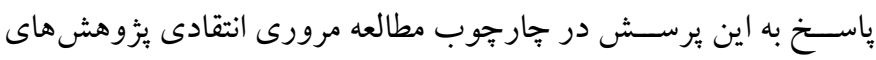

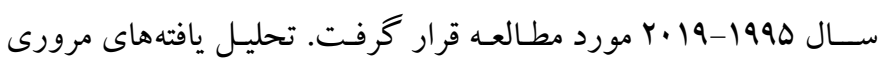

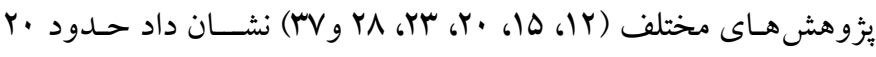
درصـد توانايى هاى ديدارى - فضـايى و خلاقيت افراد نارساخو ان بالاتر از

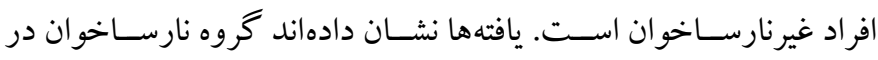
تكاليف كلى، شـاسـيى اشكال نامعمول، و شناسايى تكميل تصوير، بهتر

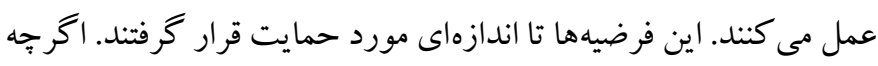

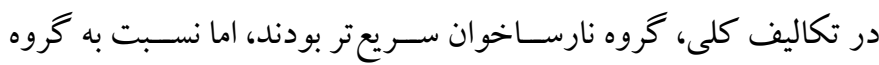
بدون نارسـاخوان در شـناسـايى اشـياء نامعمول، دقيق تر نبودند. در مرحله

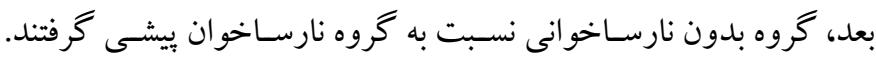

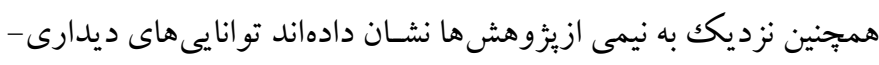

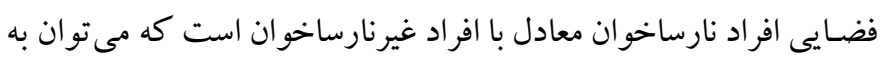

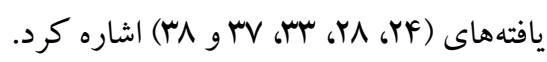

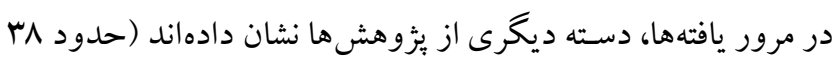
درصد) كه تو انايىهاى ديدارى- فضايى افراد نارساخوان يايين تر از افراد

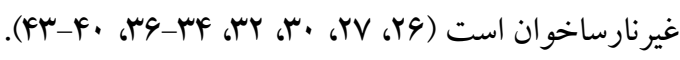
بـا وجود يافته هاى بالا مبنى بر بود و نبود برترى در افراد نارســاخوان

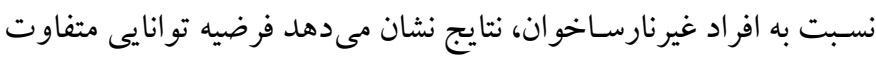

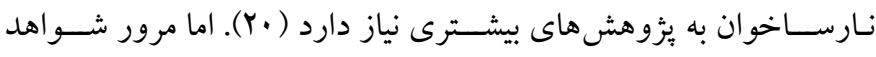

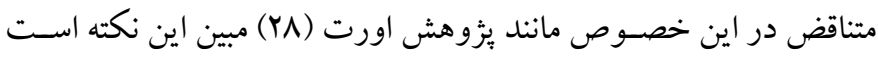

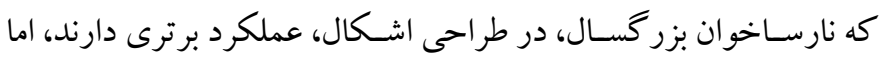

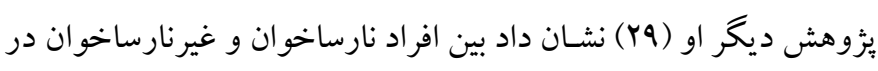
زمينه خلاقيت تفاوتى ديده نشد.

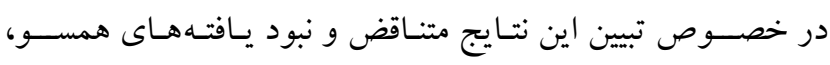

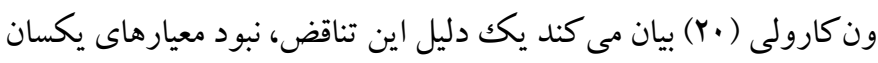
براى تشـخص و سـنش نارسـاخوانى است. ويز گى تكاليف ديدارى - 
نارساخوان ممكن است به صورت مطلق بيان نشود، در نتيجه استعدادهاى نسبى در حوزههاى شناختى يا شخصيتى وجود دارد.

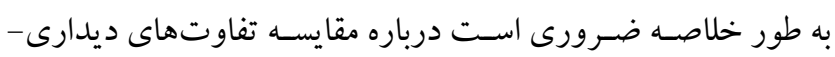

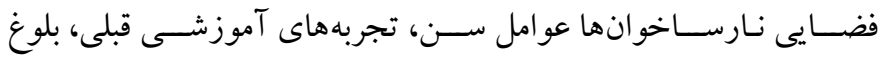

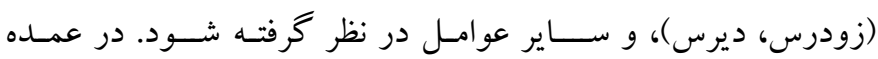

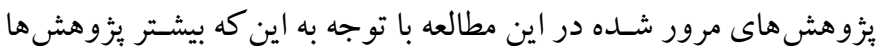

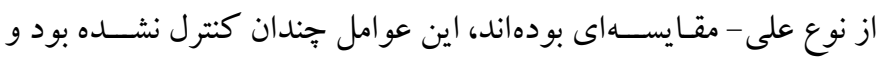
حتى در برخى مطالعات به فرايند همتاسازى اشارهاى نشده بود.

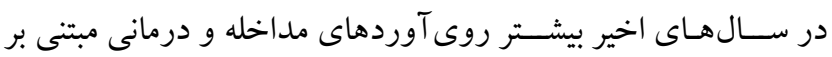
مدلهاى يزشكى و آسيبـمحور بوده و بر نقاط ضعفي، تمركز بيشترى

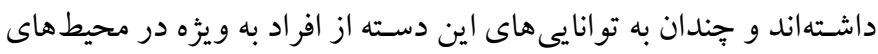
آموزشى مانند مدارس توجهاى نشـده است. نكتهاى بسيار ظريف كه در

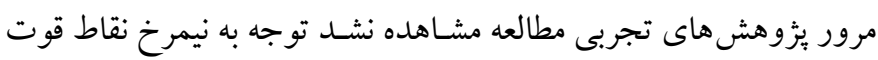

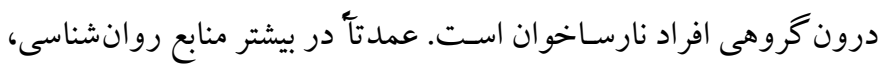

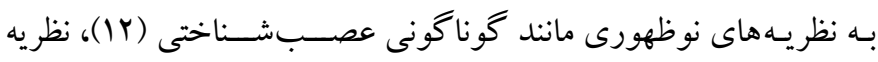

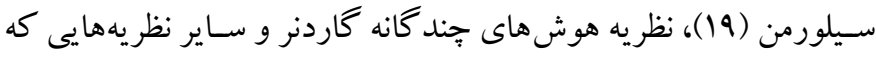
زير جتر روى آوردهـاى تفاوتمحور قرار دارند و ديدكاه نظرى مثبتى به

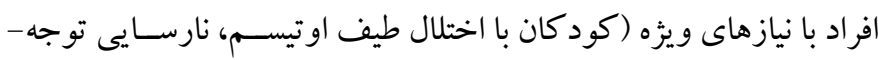

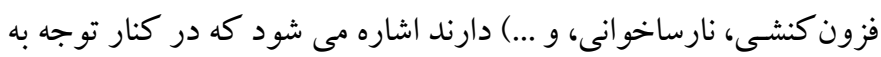
نقاط ضعف اين افر اد، به شناسايى نقاط قوت اين افر اد نيز تاكيد مى كنيند

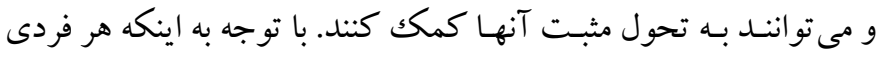

منحصربه فرد است نقاط قوت و ضعف در همه افر اد ديده مى شود.

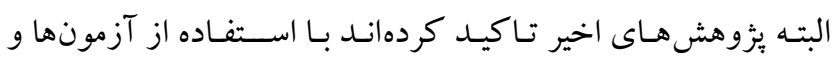

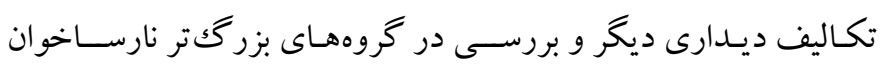

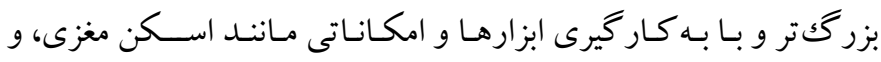
تصويربردارى هاى مغزى با امكان مشـاهده يردازش هاى شناختى مى تو ان

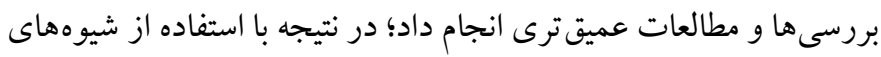
ديخر، شايد بتوان تشخيص هاى دقيقترى فر وراهم كرد.

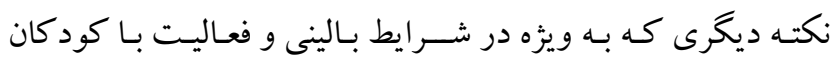

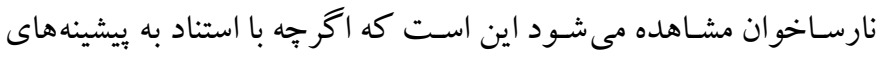

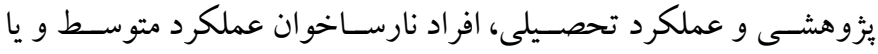

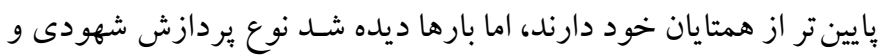

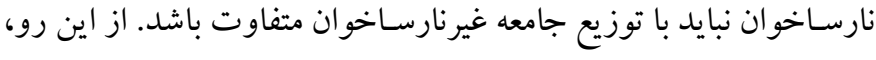

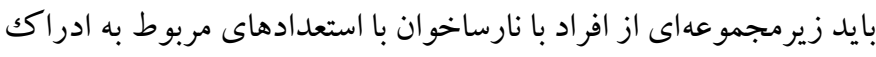

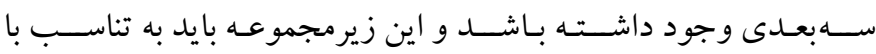
زيرمجموعهاى از افر اد غيرنارساخوان با توانايى مشابه، مقايسه شود.

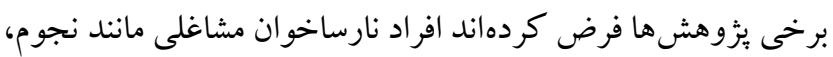

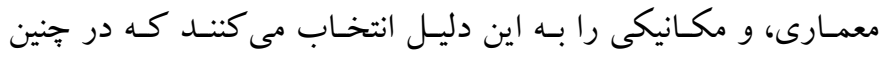
فعاليت هايى برتر هستند؛ اما يُزوهشخر ان بيان مى كنند شايد اين انتخابها،

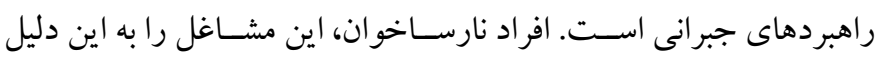

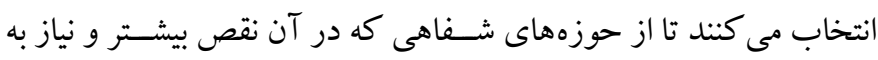

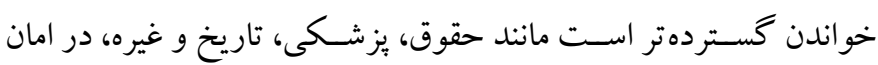

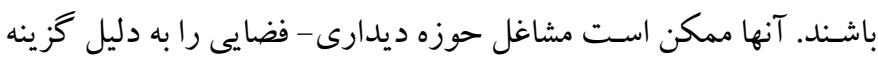
بين بدو بدتر انتخاب كنند (ساك، آس) .

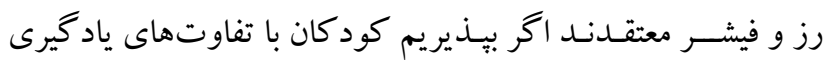

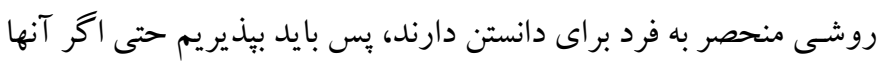

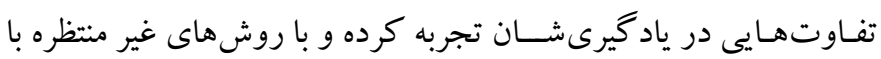

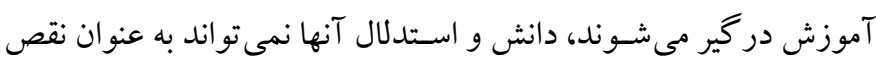

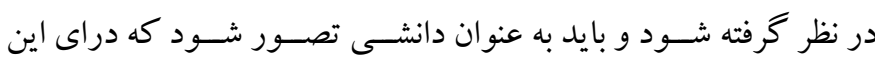

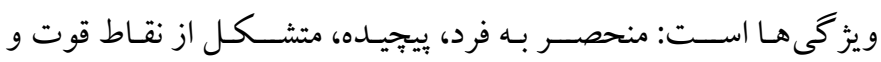

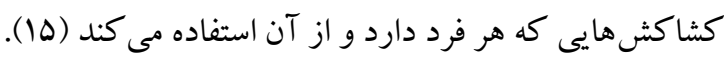

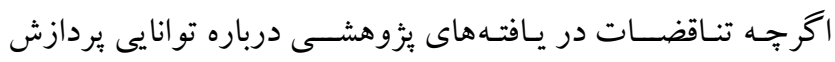

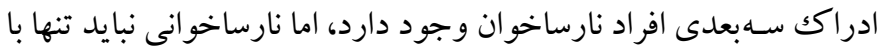

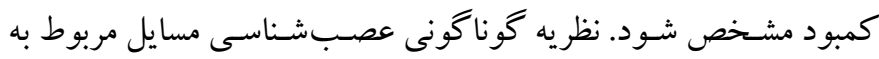

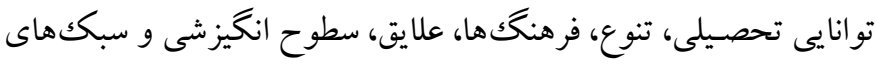

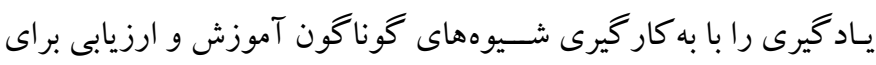

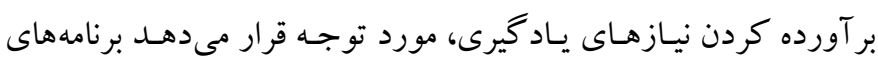

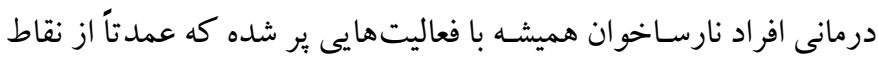

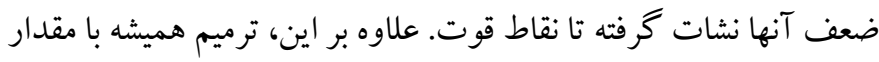

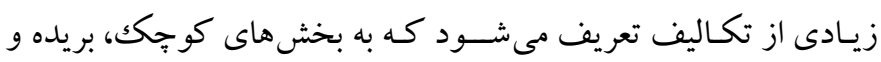

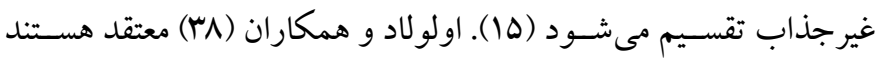
اخر جه بردازش عصسبى كه براى حل تكاليف ديدارى - فضـايى اسـتفاده

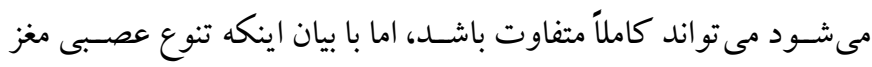


مشـاهده نشـــ. همجِين اين احتمال اسـت يُزوهش هاى ديخرى در حوزه

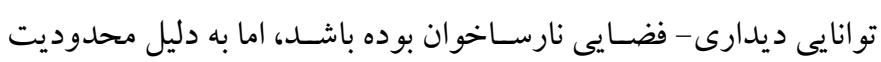

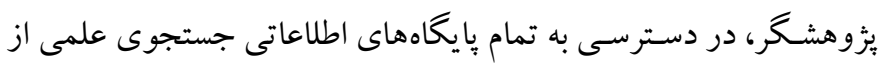
دست رفته باشند.

ملاحظات اخلاقى

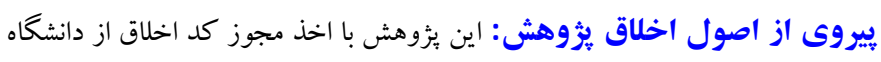
الزهرا به شماره IR.ALZAHRA.REC.1399.003 إنجام شده است. حامى مالى: اين مطالعه بدون حمايت مالى هيج گُونه سازمان و يا مؤسسه انجام شده است.

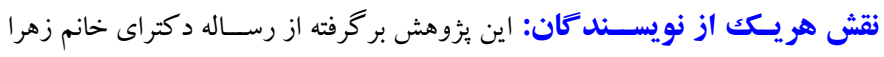

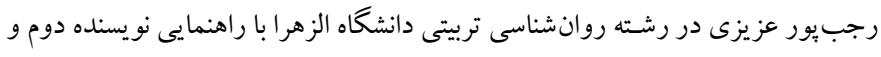

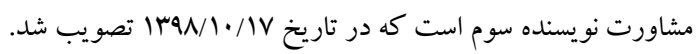

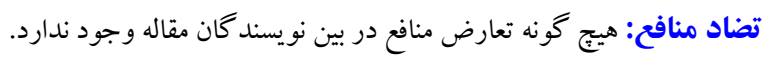

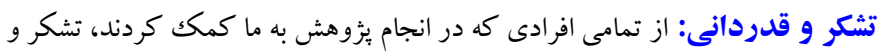

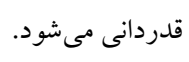

غير خطى برخى افر اد نارسـاخوان (به ويزُه افراد نارسـاخوان نوع ديدارى)

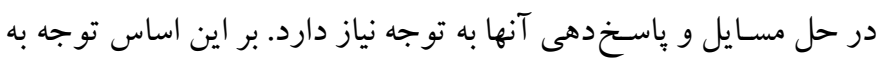
تفاوت هاى فردى با وجود نبود برترى ويثه، ضرورى است.

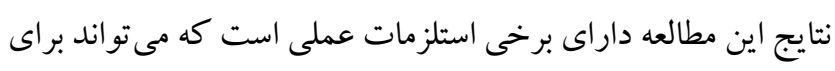

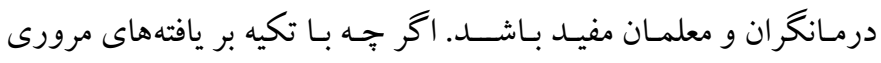

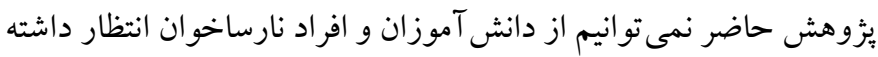

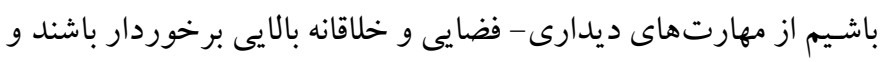

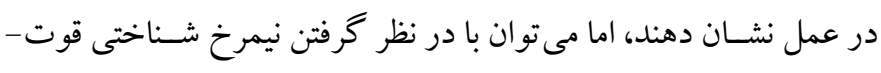

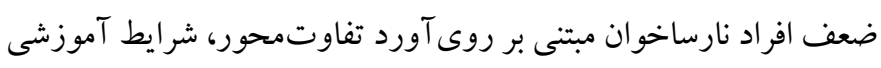

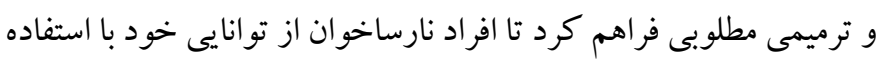

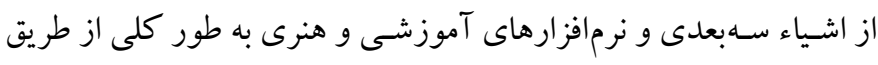

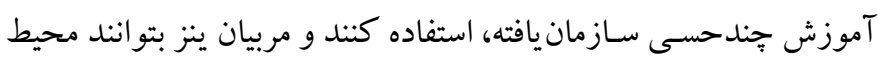
آموزشى را متناسب با نيازهاى آنها فراهم كنند.

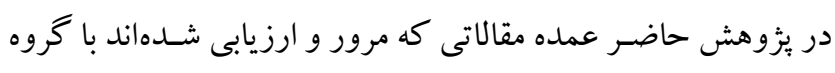

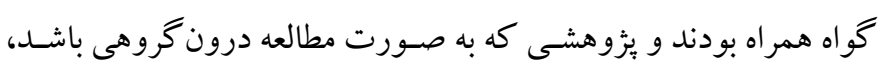




\section{References}

1. American Psychiatric Association.Diagnostic and statistical manual of mental disorders DSM_5 (5th ed.). Washington, DC: Author. 2013, :P 31. [Link]

2. Gori S, Facoetti A. How the visual aspects can be crucial in reading acquisition: The intriguing case of crowding and developmental dyslexia. J Vis. 2015; 15(1): 1-20. Doi :org/10.1167/15.1.8 [Link]

3. Adubasim I. Improving Working Memory and Processing Speed of Students with Dyslexia in Nigeria. Online Submission. 2018; 5(2):103-123. Doi: 10.26762/jee.2018.40000017 [Link]

4. Altemeier LE, Abbott RD, Berninger VW. Executive functions for reading and writing in typical literacy development and dyslexia. J Clin Exp Neuropsychol. 2008; 30 (5): 588-606. Doi: 10.1080/13803390701 562818 [Link]

5. Foy JG, Mann VA. Executive function and early reading skills. Read Writ. 2013; 26 (3): 453-472. https://eric.ed.gov/?id=EJ998204 [Link]

6. Pennington, B. F. Diagnosing learning disorders: A neuropsychological framework 2nd Ed. New York: The Guilford Press. 2009; pp 46-47. [Link]

7. Shiran A, Breznitz Z. The effect of cognitive training on recall range and speed of information processing in the working memory of dyslexic and skilled readers. J Neurolinguistics. 2011; 24(5): 524-537. Doi: org/10. 1016/j.jneuroling.2010.12.001 [Link]

8. Baddeley A. Working memory: theories, models, and controversies. Annual review of psychology. 2012; 63: 1-29. https://www.annualreviews.org/doi/full/ 10.1146/annurev-psych-120710-100422 [Link]

9. Stein. J \& capoula.z. Visual Aspects of Dyslexia. Oxford University Press in the UK. 2012; pp15-16. [Link]

10.Estévez-Pérez N, Castro-Cañizares D, MartínezMontes E, Reigosa-Crespo V. Numerical processing profiles in children with varying degrees of arithmetical achievement. J actpsy. 2019; 198:102849. Doi:org/10.1016/j.actpsy.2019.05.001 [Link]

11. Semrud-Clikeman M. Neuropsychological aspects for evaluating learning disabilities. J Learn Disabil. 2005; 38(6):563- 568. Doi:org/10.1177/0022219405038006 1301 [Link]

12. Akhavan Tafti MA, Hameedy MA, Baghal NM. Dyslexia, a deficit or a difference: Comparing the creativity and memory skills of dyslexic and nondyslexic students in Iran. Social Behavior and Personality: an international journal. 2009; 37(8): 1009-1016. Doi:org/10.2224/sbp.2009.37.8.1009 [Link]
13. Von Karolyi C, Winner E, Gray W, Sherman GF. Dyslexia linked to talent: Global visual-spatial ability. Brain lang. 2003; 85(3): 427- 431. Doi: 10.1016/ S0093-934X (03)00052-X [Link]

14. Masataka N. Implications of the idea of neurodiversity for understanding the origins of developmental disorders. Phys Life Rev. 2017; 20: 85108. Doi: 10.1016/j.plrev.2016.11.002 [Link]

15. AkhavanTafti MA, Heidarzadeh M, Khademi M. A comparison of multiple intelligences profile of students with and without learning disabilities. International Journal of Applied Psychology. 2014; 4(3): 121-125. Doi: 10.5923/j.ijap.20140403.06 [Link]

16. West TG. A future of reversals: Dyslexic talents in a world of computer visualization. Ann Dyslexia. 1992; 42(1): 124- 139. https://eric.ed.gov/?id=EJ455787 [Link]

17. Wang LC, Yang HM. The comparison of the visuospatial abilities of dyslexic and normal students in Taiwan and Hong Kong. Res Dev Disabil. 2011; 32 (3): 1052-1057. Doi: 10.1016/j.ridd.2011.01.028 [Link]

18. Geschwind N, Galaburda AM. Cerebral lateralization: Biological mechanisms, associations, and pathology. Arch Neurol; 1985; 42(6): 521-552. Doi: 10.1001/ archneur.1985.04060050026008 [Link]

19. Silverman LK. The power of images: Visual-spatial learners. Gifted Education Communicator. 2003; 34 (1): 14-17. Doi:10.1001/archneur.1985.0406005002 6008 [Link]

20. Von Karolyi C. Visual-spatial strength in dyslexia: Rapid discrimination of impossible figures. J Learn Disabil. 2001; 34 (4): 380- 391. Doi:10.1177/ 002221940103400413 [Link]

21. Eide B, Eide F. The mislabeled child: How understanding your child's unique learning style can open the door to success. Hachette Books; 2006, P: 87 [Link]

22. Kannangara CS, Carson J, Puttaraju S, Allen RE. Not all those who wander are lost: examining the character strengths of dyslexia. Global Journal of Intellectual and Developmental Disabilities. 2018; 4(5): 555648. Doi: 10.19080/GJIDD.2018.04.555648 [Link]

23. Attree EA, Turner MJ, Cowell N. A virtual reality test identifies the visuospatial strengths of adolescents with dyslexia. Cyberpsychol Behav. 2009; 12(2):163 -168. Doi: 10.1016/j. cognition.2018.06.020 [Link]

24. Duranovic M, Dedeic M, Gavrić M. Dyslexia and visual-spatial talents. Current Psychology. 2015; 34(2): 207-222. Doi:10.5901/ajis.2017.v6n1p103 [Link] 
25. Martinelli V, Camilleri D, Fenech D. Common Beliefs and Research Evidence about Dyslexic Students' Specific Skills: Is it time to reassess some of the evidence. Interdisciplinary Education and Psychology. 2018; 2(2):4. Doi:10.5901/ajis.2017. v6n1p103 [Link]

26. Klonari, A. I., \& Passadelli, A. S. (Differences between Dyslexic and Non-Dyslexic Students in the Performance of Spatial and Geographical Thinking. Review of International Geographical Education Online, 2019; 9(2): 284-303. Doi: 10.33403/rigeo. 510360 [Link]

27. Afsharian, N, Yaryari, F, Amin Alraya, F., GhelichySeke, M. To Compare Visual-Spatial Abilities and Memory in Students with and without Reading Disorder. 2014, 4 (14): 69-78. [Persian]. [Link]

28. Everatt J. The abilities and disabilities associated with adult developmental dyslexia. Journal of Research in Reading. 1997; 20(1): 13-21 Doi:.org/10.1111/14679817.00016 [Link]

29. Everatt J, Steffert B, Smythe I. An eye for the unusual: Creative thinking in dyslexics. Dyslexia. 1999; 5(1): 2846. Doi:org/10.1002/ (SICI) 1099-0909(199903) [Link]

30. Winner E, von Karolyi C, Malinsky D, French L, Seliger C, Ross E, Weber C. Dyslexia and visualspatial talents: Compensation vs deficit model. Brain Lang. 2001; 76(2): 81-110. Doi:org/10.1006/brln. 2000.2392 [Link]

31. Wolff U, Lundberg I. The prevalence of dyslexia among art students. Dyslexia. 2002; 8(1): 34-42. Doi:10.1002/dys.211 [Link]

32. Rüsseler J, Scholz J, Jordan K, Quaiser-Pohl C. Mental rotation of letters, pictures, and threedimensional objects in German dyslexic children. Child Neuropsychol. 2005; 11(6): 497-512. Doi:10.1080/09297040490920168 [Link]

33. Corlu M, Özcan O, Korkmazlar Ü. The potential of dyslexic individuals in communication design education. Behav Neurol. 2007; 18(4): 217-223. Doi: 10.1155/2007/327530 [Link]

34. Rusiak P, Lachmann T, Jaskowski P, van Leeuwen C. Mental rotation of letters and shapes in developmental dyslexia. Perception. 2007; 36(4): 617-631. Doi: org/ 10.1068/p5644 [Link]

35. Jones MW, Branigan HP, Kelly ML. Visual deficits in developmental dyslexia: relationships between nonlinguistic visual tasks and their contribution to components of reading. Dyslexia. 2008; 14(2): 95115. Doi: 10.1002/dys.345 [Link]
36. Mammarella IC, Meneghetti C, Pazzaglia F, Gitti F, Gomez C, Cornoldi C. Representation of survey and route spatial descriptions in children with nonverbal (visuospatial) learning disabilities. Brain Cogn. 2009; 71(2):173-179.

Doi:org/10.1016/j.bandc.2009.05.003 [Link]

37. Brunswick N, Martin GN, Marzano L. Visuospatial superiority in developmental dyslexia: Myth or reality? Learning and Individual Differences. 2010; 20(5):421- 426. Doi:10.13140/2.1.2328.8004 [Link]

38. Olulade OA, Gilger JW, Talavage TM, Hynd GW, McAteer CI. Beyond phonological processing deficits in adult dyslexics: atypical fMRI activation patterns for spatial problem solving Dev Neuropsychol. 2012; 37(7): 617-635. Doi: 10.1080/87565641.2012.702826 [Link]

39. Gabay Y, Gabay S, Schiff R, Ashkenazi S, Henik A. Visuospatial attention deficits in developmental dyslexia: evidence from visual and mental number line bisection tasks. Arch Clin Neuropsychol. 2013; 28(8): 829-836. Doi: 10.1093/arclin/act076 [Link]

40. Alves RJ, Nakano TD. Creativity and Intelligence in Children with and Without Developmental Dyslexia1. Paidéia (Ribeirão Preto). 2014; 24(59): 361-369. Doi:org/10.1590/1982-43272459201410 [Link]

41. Tobia V, Marzocchi GM. Cognitive profiles of Italian children with developmental dyslexia. Reading Research Quarterly. 2014; 49(4): 437-452. Doi:org/10.1002/rrq.7z7 [Link]

42. Cancer A, Manzoli S, Antonietti A. The alleged link between creativity and dyslexia: Identifying the specific process in which dyslexic students excel. Cogent Psychology. 2016; 3(1): 1190309. Doi:org/ 10.1080/23311908.2016.1190309 [Link]

43. Lecerf T, Bovet-Boone F, Peiffer E, Kieng S, Geistlich S. WISC-IV GAI and CPI profiles in healthy children and children with learning disabilities. European Review of Applied Psychology. 2016; 66(3) 101-107. Doi:org/10.1016/j.erap.2016.04.00 [Link]

44. Giovagnoli G, Vicari S, Tomassetti S, Menghini D. The role of visual-spatial abilities in dyslexia: Age differences in children's reading? Front Psychol. 2016; 7:1997. Doi: 10.3389/fpsyg.2016.01997 [Link]

45. Galli M, Cimolin V, Stella G, De Pandis MF, Ancillao A, Condoluci C. Quantitative assessment of drawing tests in children with dyslexia and dysgraphia. Hum Mov Sci. 2019; 65: 51-59. Doi: org/10.1016/j. humov.2018.05.001 [Link] 